\title{
Protein Phosphatase 1 in association with Bud14 inhibits mitotic exit in Saccharomyces cerevisiae
}

\section{Dilara Kocakaplan ${ }^{1, \ddagger}$, Hüseyin Karabürk ${ }^{1, \ddagger}$, Cansu Dilege ${ }^{1}$, Idil Kirdok ${ }^{1}$, Şeyma Nur Erkan $^{1}$, Ayse Koca Caydasi ${ }^{1, *}$}

1. Department of Molecular Biology and Genetics, Koç University, Istanbul, Turkey

These authors contributed equally to this work

*Corresponding author

E-mail: aykoca@ku.edu.tr

Running title: Glc7-Bud14 inhibits mitotic exit

Key words: Checkpoint / Mitosis / Mitotic exit / Protein phosphatase 1/ Spindle Position Checkpoint

\begin{abstract}
Saccharomyces cerevisiae, also known as the budding yeast, orients and elongates its mitotic spindle along its polarity axis in order to segregate one copy of its genomic DNA to the daughter cell. When accurate positioning of the mitotic spindle fails, a surveillance mechanism, named the Spindle Position Checkpoint (SPOC), prevents cells from exiting mitosis unless the spindle orientation is corrected. Mutants with a defective SPOC loss their genomic integrity, become multiploid and aneuploid. Thus, SPOC is a crucial checkpoint for the budding yeast. Yet, a comprehensive understanding of how the SPOC mechanism works is missing. In this study, we identified Bud14 as a novel checkpoint protein. We showed that the mitotic exit inhibitory function of Bud14 requires its association with the type 1 protein phosphatase, Glc7. Our data indicate that Glc7-Bud14 promotes dephosphorylation of the SPOC effector protein Bfa1. Our results support a model in which Glc7-Bud14 works parallel to the SPOC kinase Kin4 in inhibiting mitotic exit.
\end{abstract}




\section{Introduction}

Budding yeast undergoes asymmetric cell division in every cell cycle and is an intrinsically polarized cell. In every cell cycle, a new cell buds on the mother cell and pinches of from this location at the end of the cell division, giving rise to a young daughter cell and an old mother cell. In order for the daughter cell to receive one copy of the duplicated genetic material, budding yeast has to segregate its chromosomes along its mother-to-bud polarity axis, which requires positioning of the mitotic spindle apparatus along this direction. The correct orientation of the mitotic spindle is achieved by two redundant pathways, namely the "early" and "late" pathways, which are dependent on the Adenomatous Polyposis Coli (APC) homolog Kar9 and the microtubule motor protein Dyn1 respectively (Adames \& Cooper, 2000; Beach et al, 2000; Li et al, 1993; Siller \& Doe, 2009).

Correct orientation of the mitotic spindle is monitored by a mitotic checkpoint named the Spindle Position Checkpoint (SPOC) in budding yeast. SPOC prevents cell cycle progression of cells that fail to orient their spindle in the mother-to-bud direction, and hence provides time for the cells to correct their spindle orientation before mitotic exit (Adames et al, 2001; Bardin et al, 2000; Bloecher et al, 2000; Pereira et al, 2000; Yeh et al, 1995). Yeast cells with defects in the spindle positioning pathways or cells with impaired microtubule function rely on the SPOC to maintain their ploidy. Absence of SPOC causes multinucleation, enucleation and aneuploidy in budding yeast. A SPOC like checkpoint also exists in Drosophila and may be present in higher eukaryotes (Cheng et al, 2008; O'Connell \& Wang, 2000; Pereira \& Yamashita, 2011).

In response to spindle mispositioning, SPOC inhibits cell cycle progression by inhibiting the Mitotic Exit Network (MEN) (Baro et al, 2017; Caydasi et al, 2010a; Caydasi \& Pereira, 2012; Weiss, 2012). MEN is a GTPase driven signaling pathway that is essential for mitotic exit in budding yeast (Jaspersen et al, 1998; Shou et al, 1999). A single conserved phosphatase, named Cdc14 triggers mitotic exit in budding yeast through inactivation of the mitotic Cyclin Dependent Kinase (CDK) and dephosphorylation of CDK targets (Manzano-Lopez \& MonjeCasas, 2020). At the anaphase onset, a transient wave of Cdc14 activation is triggered by the cdcFourteen Early Anaphase Release (FEAR) network; whereas later in anaphase the MEN promotes fully activation of Cdc14 (Jaspersen et al., 1998; Lee et al, 2001a; Rock \& Amon, 2009; Shou et al., 1999). A Ras-like small GTPase named Tem1 is the main switch located near the top of the MEN (Lee et al., 2001a; Morishita et al, 1995; Scarfone \& Piatti, 2015; 
Shirayama et al, 1994b). When bound to GTP, Tem1 initiates the MEN signaling by recruiting the Cdc15 kinase to the spindle pole bodies (centrosome equivalent in yeast, SPB) which therein activates Dbf2 kinase in association with its regulatory subunit Mob1 (Asakawa et al, 2001; Cenamor et al, 1999; Visintin \& Amon, 2001).

SPOC inhibits the MEN through inactivation of Tem1 by a bipartite GTPase Activating Complex (GAP) composed of Bfa1 and Bub2 proteins (Geymonat et al, 2002). Activity of the Bfa1-Bub2 GAP complex is tightly regulated at the level of Bfa1 phosphorylation. In cells with a correctly positioned anaphase spindle, the polo like kinase Cdc5 phosphorylates Bfal to prevent Bfa1-Bub2 GAP activity towards Tem1 (Hu et al, 2001). CDK also phosphorylates Bfal in an activating manner until anaphase when this phosphorylation is removed in a FEAR related manner (Caydasi et al, 2017). In the presence of spindle misalignment, however, Kin4 kinase phosphorylates Bfal (Maekawa et al, 2007). This phosphorylation prevents inhibitory phosphorylation of Bfa1 by Cdc5 kinase (Pereira \& Schiebel, 2005). Consequently, Bfa1-Bub2 GAP complex activity is promoted, Tem1 activity is prevented, and exit from mitosis is inhibited.

SPBs, serving as a scaffold, play a key role in mitotic exit and its timely regulation by the spindle position (Campbell et al, 2020; Gruneberg et al, 2000; Pereira \& Schiebel, 2001; Valerio-Santiago \& Monje-Casas, 2011). When the spindle is properly oriented, Bfa1-Bub2 and Tem 1 reside in a preferential, asymmetrical manner at the SPB that moves to the daughter cell (dSPB) (Molk et al, 2004; Pereira et al., 2000). On contrary, Kin4 localizes exclusively to the SPB that stays in the mother cell (mSPB) during an unperturbed anaphase (D'Aquino et al, 2005; Pereira \& Schiebel, 2005). Spindle misalignment alters SPB localization of SPOC components. Upon mispositioning of the mitotic spindle, Kin4 localizes to both SPBs (Gislene Pereira \& Schiebel, 2005). Phosphorylation of Bfa1 by Kin4 promotes binding of the 14-3-3 family protein Bmh1 to Bfa1 which causes dissociation of Bfa1-Bub2 from SPBs (Caydasi et al, 2012; Caydasi et al, 2014; Caydasi \& Pereira, 2009; Monje-Casas \& Amon, 2009). Hence, upon spindle mispositioning, the amount of Bfa1-Bub2 at both SPBs decreases, while their cytoplasmic levels increase. The release of Bfa1-Bub2 from SPBs is thought to keep Bfa1Bub2 away from the inhibitory kinase Cdc5 and thus prevent inactivation of Bfa1-Bub2 by Cdc5. However, what dephosphorylates the Cdc5 phosphorylated Bfa1 remains elusive.

Here, we identified Bud14 as a novel SPOC protein. Deletion of BUD14 rescued cold sensitivity of lte $1 \Delta$ cells, lethality of mitotic exit deficient lte $1 \Delta$ spol $2 \Delta$ cells, and growth 
defects of MEN temperature sensitive mutants. Our data showed that bud14A cells accumulated multinucleated phenotypes when spindle positioning was impaired in cells via deletion of KAR9 or DYN1. Fluorescence time-lapse microscopy revealed that bud14A cells failed to delay mitotic exit in response to spindle mispositioning. We further found that the mitotic exit inhibitory function Bud14 required its association with the type 1 protein phosphatase, Glc7. A temperature sensitive version of Glc7 (Glc7-ts) and a version of Bud14 that cannot interact with Glc7 caused SPOC deficiency and rescued growth of mitotic exit mutants. Yeast two hybrid data indicated an interaction between Bfal and Bud14 that required the presence of Bub2, which suggests that Bud14 may recognize Bfa1-Bub2. Intriguingly, bud14 $\Delta$ cells had more Bfa1-Bub2 localized to SPBs, especially to the daughter oriented SPB, suggestive of a role for Bud14 in limiting SPB-bound levels of Bfa1-Bub2. We further observed that cells lacking Bud14 accumulated hyperphosphorylated Bfa1 forms during anaphase and through in vitro phosphatase assays, we showed that Glc7-Bud14 dephosphorylated this hyperphosphorylated forms Bfa1. Our data altogether indicates that Glc7-Bud14 is a novel mitotic exit inhibitor in budding yeast that works upon spindle mispositioning. We propose a checkpoint model in which two independent mechanisms activate the checkpoint effector: first, the SPOC kinase Kin4 prevents further Cdc5 phosphorylation of Bfal by rapidly removing Bfal away from the Cdc5 kinase and second, Glc7-Bud14 dephosphorylates the Cdc5-phosphorylated Bfa1, possibly in the cytoplasm, to activate the Bfa1-Bub2 GAP complex. Both mechanisms are crucial for rapid activation of the checkpoint effector Bfa1-Bub2 upon mispositioning of the anaphase spindle. 


\section{Results}

\section{Bud14 is a Novel Mitotic Exit Inhibitor}

Lte1 is a mitotic exit activator that becomes essential for mitotic exit at cold temperatures $(<16$ ${ }^{\circ} \mathrm{C}$ ) (Shirayama et al, 1994a). Although the exact function of Lte1 in mitotic exit is not fully understood, one of the ways that Lte1 promotes mitotic exit is by preventing binding of the SPOC kinase Kin4 to the SPB that has migrated into the bud and by inhibiting its activity therein (Bertazzi et al, 2011; Falk et al, 2011). At physiological temperatures (i.e. $30^{\circ} \mathrm{C}$ ) lte $1 \Delta$ cells rely on the presence of the FEAR network to exit mitosis. Deletion of FEAR network components such as SPO12 or SLK19 in lte1A cells causes lethality due to failure of mitotic exit (Stegmeier et al, 2002). Lethality of the lte1 $\Delta$ spo12 2 double mutants can be rescued by deletion of the known mitotic exit inhibitors BFA1, BUB2 and KIN4 (D'Aquino et al., 2005; Stegmeier et al., 2002). In order to identify novel mitotic exit inhibitors, we designed a genetic screen that looked for single gene deletions rescuing lte1 $\triangle$ spo $12 \Delta$ lethality. In addition to the known mitotic exit inhibitors BFA1, BUB2 and KIN4, we identified BUD14 as a novel gene that contributes to the mitotic arrest of lte1 $\triangle$ spo12 $\triangle$ cells (data not shown). Deletion of BUD14 rescued lethality of lte1 $\triangle$ spo12A cells (Figure 1A). Deletion of BUD14 also rescued the cold sensitivity of lte1A cells (Figure 1B). This data indicates that Bud14 is a novel inhibitor of mitotic exit.

Deletion of mitotic exit inhibitors such as $B F A 1, B U B 2$ and $K I N 4$ also rescues growth lethality of mitotic exit network (MEN) mutants. Thus, we next asked whether deletion of BUD14 also promotes the growth of MEN mutants. For this, we deleted BUD14 in several MEN-ts mutants (Jaspersen et al., 1998) and compared their growth at different temperatures. In line with its mitotic exit inhibitory role, deletion of $B U D 14$ promoted growth of $d b f 2-2, c d c 15-1$, mob1-67 and $c d c 5-10$ mutants at $37{ }^{\circ} \mathrm{C}, 35{ }^{\circ} \mathrm{C}, 33{ }^{\circ} \mathrm{C}$ and $35{ }^{\circ} \mathrm{C}$ respectively (Figure 1C). Notably, bud144 did not rescue the growth of the cdc14-2 mutant (Figure 1C). Cdc14 is the essential phosphatase that is activated at the very downstream of the MEN pathway. The fact that bud14 1 rescues the MEN-ts mutants but not cdc14-ts suggests that Bud14 may function upstream of the MEN pathway.

\section{bud14 $\Delta$ cells are unable to inhibit mitotic exit upon spindle mispositioning}

The known mitotic exit inhibitors Bfa1, Bub2 and Kin4 are key components of the Spindle Position Checkpoint (SPOC), which is a surveillance mechanism that inhibits the MEN upon 
mispositioning of the anaphase spindle. We next, investigated whether Bud14 has a role in

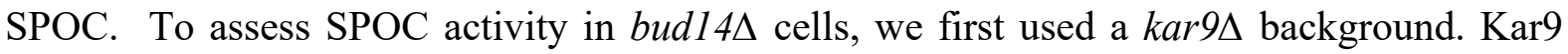
(homolog of the mammalian tumor suppressor Adenomatous polyposis coli, APC) is a microtubule and actin associated protein, that links the astral microtubules with the actin cables to allow for spindle positioning along the mother-to-daughter polarity axis (Miller \& Rose, 1998). Deletion of KAR9 causes frequent spindle mispositioning at $30{ }^{\circ} \mathrm{C}$ and above. These cells, however, can correct their mispositioned spindle due to the presence of another spindle positioning pathway that is dependent on the minus-end directed microtubule motor protein Dynein (Eshel et al, 1993; Li et al., 1993; Miller \& Rose, 1998). Upon spindle mispositioning, cells with a functional SPOC arrest in anaphase until the spindle position is corrected; whereas SPOC deficient cells continue cell cycle progression resulting in formation of multinucleated

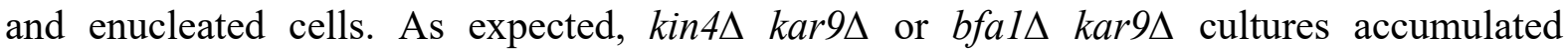

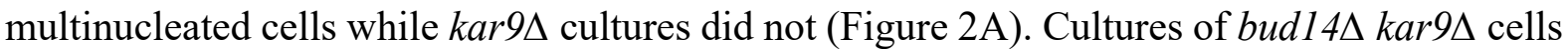
also accumulated such multinucleated phenotypes, indicating that Bud14 is crucial for maintenance of ploidy in cells lacking KAR9 (Figure 2A)

Bud14 was shown to have a role in promoting dynein/dynactin activity at the bud cortex (Knaus et al, 2005). Considering the function of Dynein in spindle positioning, we asked whether the reason of multinucleation in bud14 $\operatorname{kar} 9 \Delta$ cells was the lack of Dynein activity which in turn would prevent re-aligning of the anaphase spindle. If this was the case, we would expect to see no significant multinucleation phenotype when the SPOC activity was assayed in a background that already lacked Dynein activity. For this we used $d y n 1 \Delta$ cells that are deleted for the dynein

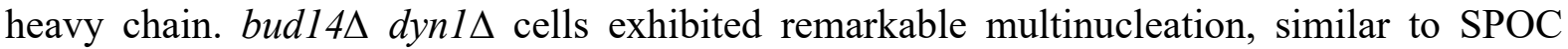
deficient kin4s dyn1 $\Delta$ cells (Figure 2B). This data indicates that the role of Bud14 in Dynein activation does not account for the observed multinucleation phenotype of bud14 $\operatorname{kar} 9 \Delta$.

Next, we analyzed the timing of mitotic exit in bud14 $\Delta$ cells during spindle misalignment and normal alignment in a GFP-TUB1 kar9 9 background. GFP-TUB1 served as a spindle marker. kar9 $9 \Delta$ population contains cells with misaligned spindles as well as cells with normally aligned spindles, and thus allows analysis of anaphase duration in both cases. Cells were imaged through fluorescence time-lapse microscopy for 90 minutes with 1 min time-resolution at 30 ${ }^{\circ} \mathrm{C}$. Anaphase duration was calculated as the time elapsed between the start of fast spindle elongation and the spindle breakage, which are indications of anaphase onset and mitotic exit respectively. The majority of kar9 $9 \Delta$ cells with misaligned spindles stayed arrested with an 
intact spindle during the course of the time-lapse movie, whereas kin $4 \Delta$ kar9 $9 \Delta$ cells with

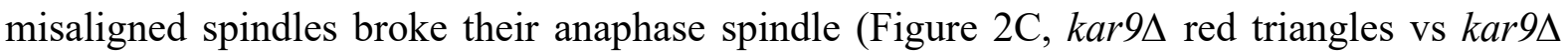
kin $4 \Delta$ black squares). bud $14 \Delta$ kar9 $\Delta$ cells with misaligned spindles also broke their spindle as an indication of their deficiency in keeping the SPOC arrest (Figure 2C, kar9 $9 \Delta$ bud14 , black squares). These data altogether suggest that Bud14 is needed as a part of the SPOC mechanism to arrest the cells in mitosis upon spindle mispositioning.

\section{Bud14 inhibits mitotic exit though its interaction with Glc7}

Bud14 is a regulatory subunit of the type I Protein phosphatase (PP1) Glc7 (Cullen \& Sprague, 2002; Knaus et al., 2005; Lenssen et al, 2005). Therefore, we asked whether Bud14 exerts its mitotic exit inhibitory role through Glc7. To address this question, we impaired Glc7-Bud14 function using several mutants. First, we used a mutant version of Bud14 that cannot bind Gcl7 (bud14-F379A) (Knaus et al., 2005) and analyzed its ability to rescue ltel $\Delta$ cold sensitivity. Deletion of BUD14 rescued the growth of lte $1 \Delta$ cells at $16^{\circ} \mathrm{C}$ as shown earlier (Figure 1B). Introducing wild type BUD14 but not the bud14-F379A mutant into lte $1 \Delta$ bud14A cells restored cold sensitivity of lte1s cells (Figure 3A). This data indicates that Glc7-Bud14 interaction is essential for mitotic exit inhibitory function of Bud14. In line with this notion, a temperature sensitive GLC7 mutant glc7-12 (glc7-ts) (Andrews \& Stark, 2000; Cheng \& Chen, $2010)$, rescued the lethality of ltel $\Delta$ spo $12 \Delta$ cells at its semi-permissive temperature $\left(33^{\circ} \mathrm{C}\right)$, but not at its permissive temperature $\left(18^{\circ} \mathrm{C}\right.$ ) (Figure 3B, compare lte $1 \Delta$ spo $12 \Delta$ glc7-ts cells on 5 FOA plates at $18{ }^{\circ} \mathrm{C}$ vs $33^{\circ} \mathrm{C}$ ). These data altogether suggest that Glc7-Bud14 complex has a mitotic exit inhibitory function.

Next, we investigated functional importance of Glc7-Bud14 interaction in SPOC functionality.

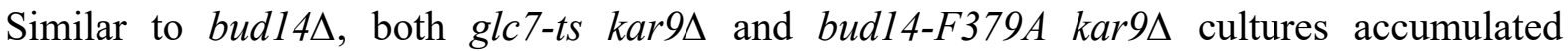
multinucleated cells (Figure 3C-3D), indicating that the mitotic exit inhibitory function of Glc7-Bud14 is also crucial for SPOC function.

Bud14 contains an SH3 domain at its amino terminal (amino acids 262-318), deletion of which diminishes Bud14 bud cortex localization (Knaus et al., 2005). Similar to bud14A, bud14-

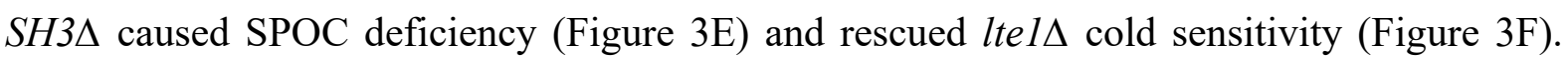
Thus, SH3 domain of Bud14 is important for Bud14 function in mitotic exit. Importantly, lack of SH3 domain also diminishes ability of Bud14 to interact with Glc7 (Knaus et al., 2005). Considering that Bud14 Glc7 interaction is necessary for this role, it may be due to impairment 
of Glc7-Bud14 interaction in the bud14-SH3 $\Delta$ mutant that causes loss of mitotic exit inhibitory function of Bud14. Additionally, Bud14 cortex localization may as well be crucial for Bud14 mitotic exit inhibitory function via alternative mechanisms.

\section{Bud14's function in SPOC is independent of its role in formin regulation}

Bud14 is an inhibitor of the formin Bnrl (Chesarone et al, 2009). It regulates actin cable formation through its formin-regulatory motif (amino acids 135-150) (Chesarone et al., 2009; Eskin et al, 2016). Bud14's function in controlling formin activity also requires its interaction with KELCH domain proteins Kell and Kel2 (Gould et al, 2014). We addressed the contribution of actin regulatory role of Bud14 to its mitotic exit inhibitory function through two independent approaches. First, we made use of the bud14-5A mutant whose forminregulatory motif is disrupted by five alanine amino acid substitutions at Bud14 residues 135 and 137-140 (Eskin et al., 2016). Ectopic expression of bud14-5A on a centromeric plasmid

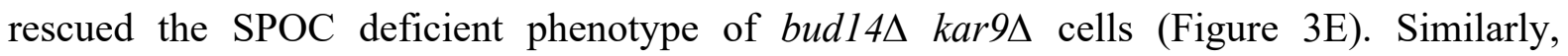
expression of bud14-5A in lte $1 \Delta$ bud $14 \Delta$ cells complemented the BUD14 deletion by restoring

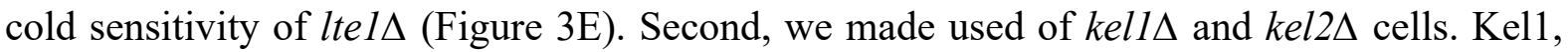
Kel2 and Bud14 forms a stable complex that regulate the formin Bnr1. Any missing protein

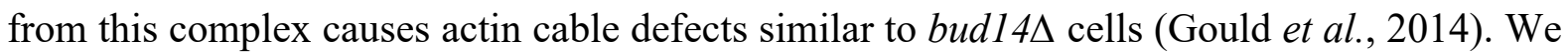
reasoned that if Kel1-Kel2-Bud14 complex that is crucial for actin regulation is also important for SPOC functionality, deletion of KEL1 or KEL2 would cause SPOC deficiency similar to

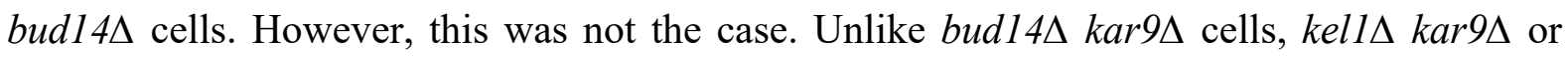
kel2A kar9A cells did not display a SPOC deficient phenotype (Figure 3G). These data altogether suggest that Bud14 function in SPOC is independent of its role in actin cable regulation.

Interestingly, deletion of KEL1 also rescues cold sensitivity of lte $1 \Delta$ similar to deletion of BUD14 (Hofken \& Schiebel, 2002; Seshan et al, 2002) (Figure 3H). Synthetic lethality of ltel $\Delta$ spo $12 \Delta$ on the other hand, can only be slightly rescued by the deletion of KEL1, whereas deletion of $B U D 14$ in lte $1 \triangle$ spo $12 \Delta$ cells exhibits a more pronounced growth rescue phenotype (Figure 3I). Deletion of KEL2 however does not rescue lte1 $\triangle$ spo12 $\triangle$ lethality, while it only has a minor impact on cold sensitivity of lte $1 \Delta$ cells (Figure 3H-3I). These data agree with previous reports that Kell and Kel2 has a mitotic exit inhibitory function (Geymonat et al, 2010; Hofken \& Schiebel, 2002; Seshan et al., 2002) and suggest that this function of Kel1 and 
Kel2 in mitotic exit inhibition differs from that of Bud14 as Kel1/Kel2 are not influencing the SPOC.

\section{Bud14 does not work in Kin4 branch of SPOC}

To this end, we showed that Glc7-Bud14 has a role in mitotic exit inhibition in cells with misaligned spindles. Intriguingly, even though BUD14 deletion caused SPOC deficiency, duration of anaphase in bud14 $\operatorname{kar} 9 \Delta$ cells was slightly longer during spindle misalignment than during spindle normal alignment (Figure 2C, bud14A, squares vs circles). Similar phenomenon was also observed in $\operatorname{kar} 9 \Delta \operatorname{kin} 4 \Delta$ cells (Figure $2 \mathrm{C}$, kin4 4 , squares vs circles) (Caydasi et al., 2017; Falk et al, 2016b). This indicates that in the absence of Bud14 or Kin4, cells are still able to delay mitotic exit albeit for short time. In contrast, cells in which both KIN4 and BUD14 were deleted did not exhibit any delay in mitotic exit upon spindle mispositioning (Figure 2C, $\operatorname{kar} 9 \Delta$ bud14 $\operatorname{kin} 4 \Delta$ black squares vs circles). Thus, KIN4 and BUD14 deletion show an additive effect. This data suggests that Kin4 and Bud14 work in parallel to keep the mitotic arrest in cells with misaligned spindles. In line with this notion, the percentage of multinucleated cells in kin $4 \Delta$ bud $14 \Delta$ kar $9 \Delta$ was greater than that of kin $4 \Delta$ kar $9 \Delta$ and bud $14 \Delta$ kar9 $9 \Delta$ but was similar to the $b f a 1 \Delta$ kar $9 \Delta$ (Figure $2 \mathrm{~A}$ ). Likewise, multinucleation

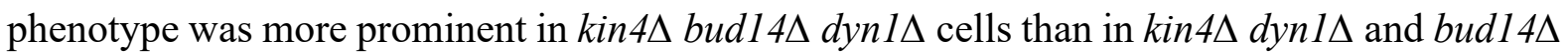
dyn $1 \Delta$ cells (Figure $2 \mathrm{~B}$ ).

Kin4 is the key SPOC kinase that phosphorylates Bfa1 upon spindle misalignment to promote Bfa1-Bub2 GAP activity. Kin4 overexpression blocks exit from mitosis through constitutive Bfa1-Bub2 activation and thus results in lethality (D'Aquino et al., 2005). This lethality can be rescued by deletion of $B F A 1$ or $B U B 2$, which are the most downstream SPOC components. Lethality of Kin 4 overexpression can as well be rescued by deletion of RTS1 or ELM1, which are Kin4 regulators, and deletion of $B M H 1$, which works downstream of KIN4 (Caydasi et al, 2010b; Caydasi et al., 2014). Unlike aforementioned gene deletions, deletion of BUD14 did not rescue the lethality of Kin4 overexpression (Figure S1A). Thus, overproduced Kin4 is still able to activate Bfal constitutively in the absence Bud14. In addition, Kin4 localization or mobility on SDS-PAGE was not altered in cells lacking Bud14 (Figure S1B-S1C), indicating that Bud14 does not act upstream of Kin4. These data altogether are in support of our conclusion that Bud14 does not work in the Kin4 branch of SPOC, it rather acts in a pathway parallel to Kin4 to prevent mitotic exit. 


\section{Bud14 interacts with Bfa1 in the yeast two hybrid system}

We sought to understand whether Bud14 interacts with SPOC proteins. For this, we performed a yeast two hybrid assay. We used Bfa1, Bub2 and Kin4 as a bait and Kel1 as a positive control in this assay. Formation of a blue color indicates activation of the $\beta$-galactosidase gene and hence physical interaction of LexA DNA binding domain fused with Bud14 (PMM5-Bud14) and Gal4-Activation Domain fused with the bait protein (pMM6-Bait protein). We observed blue color formation in cells bearing pMM5-Bud14 and pMM6-Kel1 as expected due their known physical interaction (Gould et al., 2014; Krogan et al, 2006; Neller et al, 2015). We observed a similar interaction between Bud14 and Bfa1 but not Bub2 or Kin4 (Figure 4A). Intriguingly, deletion of BUB2 but not KIN4 ceased blue color formation in cells with pMM5Bud14 and pMM6-Bfa1, indicating that Bud14-Bfa1 interaction is dependent on presence of Bub2 (Figure 4B). Although we could observe an interaction in the yeast two hybrid system we could not detect Co-IP between Bfa1-Bud14, neither we could detect an interaction between Bub2-Bud14, which may be an indication of the transient nature of Bud14-Bfa1 interaction.

\section{Bud14 limits the amount of Bfa1-Bub2 and Tem1 at SPBs but does not affect Bfa1 symmetry upon spindle mispositioning}

SPOC functionality relies on a radical change in SPB localization of Bfa1-Bub2. When the spindle is properly oriented, Bfa1-Bub2 preferentially localizes to the SPB that moves to the daughter cell (dSPB). Upon spindle misalignment Bfa1-Bub2 is released from dSPB, hence low levels of Bfa1-Bub2 is attained at both SPBs. We thus asked whether SPB localization of Bfa1-Bub2 is altered in the absence of Bud14. First, we compared the SPB-bound levels of Bfa1-GFP at SPBs in wild type and bud14A cells with normally aligned anaphase spindles (spindle length $>3 \mu \mathrm{m}$ ) (Figure 5A). To our surprise, more Bfa1-GFP was localized at SPBs in bud $14 \Delta$ cells compared to wild type cells. This difference was more pronounced at the dSPB. Importantly, increased Bfa1-GFP signal at the dSPB of bud14A cells returned to wild type levels when BUD14 was introduced in these cells on a plasmid (Figure 5B). Bub2-GFP and Tem1-GFP dSPB localization was also remarkably higher in bud14A cells than wild type cells (Figure S2A-2B). Such increase in SPB-bound levels of Bfa1-Bub2 and Tem1 was not restricted to anaphase but was also present before anaphase onset (spindle length $=1,5-2 \mu \mathrm{m}$ ) (Figure S2C). 
We next analyzed SPB-bound Bfa1 levels in cells with misaligned anaphase spindles. Similar to the situation in cells with correctly aligned spindles, bud14 $\operatorname{kar} 9 \Delta$ cells with misoriented spindles had more Bfa1-GFP at their SPBs than kar9D cells, however less Bfa1-GFP compared

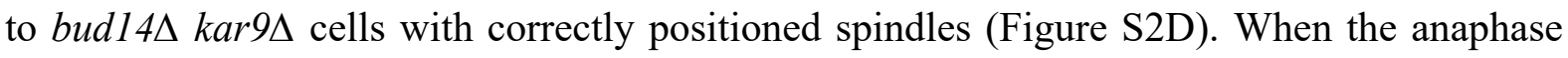
spindle elongates in the wrong direction, phosphorylation of Bfa1 by Kin4 causes dissociation of Bfa1-Bub2 from dSPB. Consequently, SPB localization of Bfa1-GFP changes from asymmetric (more at the dSPB than mSPB) to more symmetric (similar at both SPBs) upon

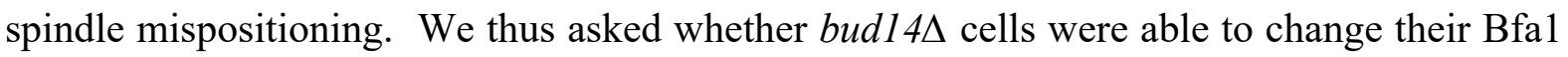
localization from asymmetric to symmetric in response to spindle misalignment. As a measure of signal asymmetry at SPBs, we analyzed the ratio of Bfa1-GFP at SPBs both in cells with correctly aligned and misaligned anaphase spindles (Figure 5C). For this, we used the kar9D background that allowed us to observe cells with normal and mis-positioned spindles in the same population. In response to spindle mispositioning, Bfa1-GFP asymmetry was drastically

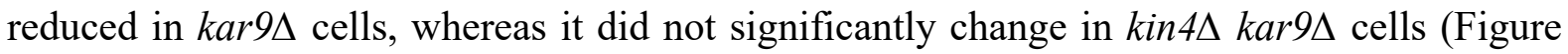
5C). Similar to kar9 $9 \Delta$ cells, Bfa1-GFP asymmetry was also greatly decreased in bud14 $\operatorname{kar} 9 \Delta$ cells when the spindle was mispositioned (Figure 5C). We also analyzed the behavior of Bfa1GFP through time-lapse experiments. Consistent with previous reports, SPB bound levels of Bfa1-GFP in kar9s cells drastically decreased within few minutes after elongation of the anaphase spindle in the wrong direction (Caydasi \& Pereira, 2009) (Figure S3A). Bfa1-GFP

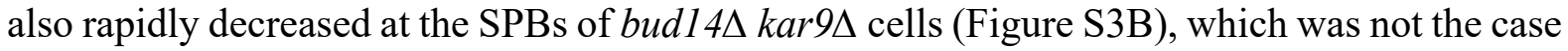
for $\operatorname{kar} 9 \Delta \operatorname{kin} 4 \Delta$ cells (Figure S3C). Thus, unlike Kin4, Bud14 does not promote a change in SPB localization of Bfal in response to spindle mispositioning, but rather causes an overall increase in the levels of SPB-bound Bfa1 regardless of the spindle position. This notion is in line with our previous conclusion that Bud14 does not work via Kin4 branch of SPOC.

\section{Bud14 promotes Bfa1 dephosphorylation during anaphase}

We next investigated whether Bud14 impinges on Bfa1phosphorylation. For this, we made use of cells bearing Gal1-UPL-TEM1, which leads to a telophase arrest in glucose containing medium via depletion of Tem1. Wild type cells arrest in telophase with hyperphosphorylated Bfa1 (Bertazzi et al., 2011; Hu et al., 2001). This form of Bfal is established to be Cdc5dependent and hence inactive ( $\mathrm{Hu}$ et al., 2001). ltels cells fail to accumulate such hyperphosphorylated Bfa1 due to localization of Kin4 at both SPBs (Figure 6A-6B and Figure S4A) (Bertazzi et al., 2011; Falk et al., 2011). SPB localized Kin4 phosphorylates Bfa1 which 
in turn prevents Cdc5 phosphorylation of Bfa1. Thus, Gal1-UPL-TEM1 lte1 $\Delta$ cells arrest in late anaphase similar to a SPOC activated state. Consequently, Bfal hyperphosphorylation is restored in lte $1 \Delta$ kin4 4 cells (Bertazzi et al., 2011) (Figure 6A-6B). Similar to deletion of KIN4, deletion of BUD14 in lte1 $1 \Delta$ cells also resulted in appearance of slow migrating Bfal forms during anaphase (Figure 6A-6B, $t \geq 75$ min, cells with separated nucleus $\geq \% 80$ ). Notably, Kin4 was localized at both SPBs of lte1s cells during anaphase independently of BUD14 (Figure S4). Thus, we conclude that Glc7-Bud14 promotes Bfa1 dephosphorylation in lte1s cells independently of Kin4.

In order to understand whether Glc7-Bud14 dephosphorylates Bfa1, we took two approaches. First, we asked whether inactivation of Glc7 in total protein extracts of telophase arrested cells would lead to a mobility shift in Bfa1-3HA. To inhibit Glc7 we used okadaic acid. Okadaic acid is a PP1 and PP2 inhibitor, lower concentration of which is sufficient to inhibit PP2 (1-2 $\mathrm{nM}$ ) whereas a thousand times more okadaic acid is required to inhibit PP1 (Bialojan \& Takai, 1988; Cohen et al, 1989a; Cohen et al, 1989b). We obtained total native protein extracts from telophase arrested Gal1-UPL-TEM1 kin $4 \Delta$ cells in the absence of any phosphatase inhibitor or in the presence of $2 \mathrm{nM}$ or $1,5 \mu \mathrm{M}$ okadaic acid to inhibit PP2 only or both PP1 and PP2 respectively (Figure 6C). Addition of $1,5 \mu \mathrm{M}$ but not $2 \mathrm{nM}$ okadaic acid resulted in an upshift of Bfa1-3HA (Figure 6C). This data indicates that first, Glc7 in the cell extracts of telophase arrested cells promotes dephosphorylation of Bfa1-3HA.

Next, we performed an in vitro dephosphorylation assay. For this, we enriched Bfa1-3HA from kin4 $\triangle$ Gal1-UPL-TEM1 cells arrested in telophase through depletion of Tem1 and incubated it with immunoprecipitated Glc7-TAP or Bud14-TAP in the presence or absence of okadaic acid. Addition of Glc7-TAP in the phosphatase reaction caused a down shift of Bfa1-3HA (Figure $6 \mathrm{D}$, lane 1 versus 2). This downshift was still prominent in the presence of $2 \mathrm{nM}$ okadaic acid but not when 1,5 $\mu \mathrm{M}$ okadaic acid was added (Figure 6D, lane 3 versus 4). Similarly, immunoprecipitated Bud14-TAP also caused a downshift in Bfa1-3HA (Figure 6D, lane 1 or 4 versus 5) which was diminished in the presence of 1,5 $\mu \mathrm{M}$ okadaic acid. These data altogether show that hyperphosphorylated Bfa1 is dephosphorylated by Glc7-Bud14.

\section{Bud14 bud cortex localization is reduced during late anaphase}

Bud14 was shown to localize at bud tips, bud cortex and bud neck in a cell cycle dependent manner (Knaus et al., 2005). We analyzed Bud14 localization specifically in cells with 
misaligned and normally aligned anaphase spindles. During early- and mid-anaphase (Figure $7 \mathrm{~A}$, spindle length $3-5 \mu \mathrm{m}$ and 5-6 $\mathrm{m}$ ) majority of cells with normally aligned spindles had Bud14-GFP enriched at the bud cortex. However, in cells with misaligned spindles Bud14 cortex localization was significantly decreased (Figure 7A). Intriguingly, in cells with correctly aligned spindles Bud14-GFP was also diminished from the bud cortex during late anaphase (spindle length $>6 \mu \mathrm{m}$ ), which led us hypothesize that the observed reduction in Bud14 bud cortex localization in cells with misaligned spindles might be a consequence of a prolonged anaphase arrest. To test this, we monitored Bud14-GFP localization through time lapse experiments. In consistence with previous reports, Bud14-GFP localized to the future bud sites at the start of the cell cycle and enlarged there like a crest shape at the bud cortex as the bud grew. As the spindle elongated in correct direction the bud cortex localization reduced gradually and finally disappeared as it started to accumulate at the bud neck (Figure 7B, upper cell, where start of anaphase is marked with an asterisk). Bud neck accumulation of Bud14GFP coincided with spindle breakdown (Figure 7B, upper cell, indicated with an arrow) which marks the end of mitosis. When the anaphase spindle was misaligned, Bud14 localized to the bud tip similar to cells with a normally aligned spindle (Figure 7B, lower cell, where start of the anaphase is marked with an asterisk). Bud14 localization at the bud cortex gradually disappeared in these cells as they stayed arrested in anaphase, in a way similar to cells with correctly aligned spindles (Figure 7B, lower cell). This data suggests that the reduced cortex localization occurs after spindle misalignment and is possibly a consequence of the mitotic arrest rather than a direct response. 


\section{Discussion}

SPOC is a surveillance mechanism that inhibits mitotic exit in response to spindle mispositioning. Protein phosphorylation and localization play a key role in SPOC. Especially the activity of Bfa1, the most downstream effector of the SPOC is tightly controlled with respect to the spindle orientation through phosphorylation by the polo like kinase Cdc5 and the mother specific kinase Kin4 in an opposing manner. Phosphorylation of Bfa1 in turn affects localization of Bfa1-Bub2 and hence the activity and the localization of the GTPase Tem1 at SPBs. Despite the knowledge on Bfa1 phosphorylating kinases, knowledge on phosphatases counteracting these kinases has been limited. In this study we established Glc7-Bud14 as a novel SPOC component that dephosphorylates Bfa1. Our work supports a model where Bfa1Bub2 is activated by Glc7-Bud14 (Figure 8).

\section{Glc7-Bud14 is a SPOC component}

Our study identified Glc7, the budding yeast protein phosphatase 1, in association with its regulatory subunit Bud14 as a novel SPOC component that inhibits mitotic exit upon spindle mispositioning. Several lines of evidence led us to this conclusion. First, similar to other SPOC proteins, $B U D 14$ deletion rescued growth of several mutants impaired in mitotic exit, including the cold sensitive ltel $\Delta$ cells, the temperature sensitive MEN mutants (cdc15-1, dbf2-2, cdc510 and mob1-67), and the synthetic lethal lte1s spo12 $\Delta$ cells. Impairment of Glc7 function via

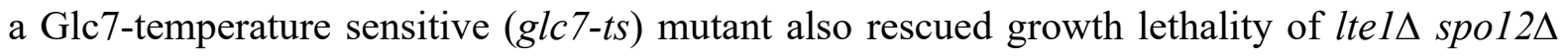
cells. In addition, a Bud14 mutant that cannot bind Glc7 (bud14-F379A) (Knaus et al., 2005) also rescued cold sensitivity of lte $1 \Delta$ cells. Second, similar to other SPOC proteins, BUD14 deletion caused accumulation of multinucleated cells when spindle misalignment was induced in cells by deletion of KAR9 or DYN1, implying that bud14 $\triangle$ cells are deficient in arresting upon mispositioning of the anaphase spindle. Of importance, similar to bud14A, glc7-ts and the bud14-F379A mutants were also SPOC deficient. Bud14 was implicated in the Dynein pathway of spindle positioning (Knaus et al., 2005). However, deletion of BUD14 caused accumulation of multinucleated phenotypes not only in kar9 $9 \Delta$ but also in $d y n 1 \Delta$ backgrounds indicating that the function of Bud14 in Dynein activation is not contributing to the observed multinucleation phenotype. In line with this notion, time-lapse analysis revealed that bud14A kar9 $9 \Delta$ cells exited mitosis with similar timing regardless of the spindle position. Of importance

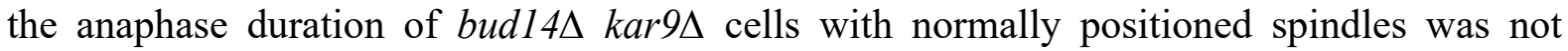
different than that of kar9D cells. Thus, similar to other SPOC components, absence of BUD14 
does not affect the timing of mitotic exit when the spindle is correctly positioned, but it is crucial for delaying exit from mitosis when the spindle is misoriented.

\section{Glc7-Bud14 works in a pathway parallel to Kin4}

Our data showed that Bud14 does not work in the Kin4 branch of SPOC. First, Kin4 localization and phosphorylation did not depend on Bud14. Second, Kin4 overexpression still caused toxicity in BUD14 deleted cells indicating that Kin4, when produced at high levels, is able to keep Bfa1 away from the SPB and Cdc5. Furthermore, time-lapse analysis of Bfa1 localization during spindle misalignment showed that Bfal is being removed from SPBs of bud14 14 cells with misaligned spindles, while removal of Bfa1 from SPBs is largely a Kin4 dependent process (Caydasi \& Pereira, 2009; Monje-Casas \& Amon, 2009). Thus, Kin4 is able to exert its effect on Bfal in the absence of BUD14. These data altogether exclude the possibility that Bud14 works through Kin4 branch of the SPOC and suggests a model in which Glc7-Bud14 prevents mitotic exit of cells with misaligned spindles in a way parallel to Kin4. In support of this model, we observed an additive decrease in anaphase duration of kin $4 \Delta$ bud1 $14 \Delta$ cells with misaligned spindles compared to the cells bearing single gene deletions of either KIN4 or BUD14. Importantly, kin $4 \Delta$ bud14 1 cells completely failed to delay mitotic exit

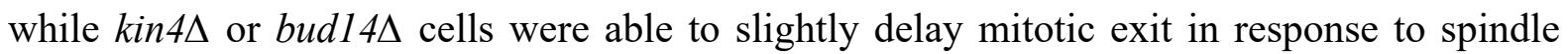
misorientation (Figure 2C). Accordingly, kin $4 \Delta$ bud14 $\Delta$ cells were as SPOC deficient as bfa $1 \Delta$ cells (Figure 2A). Thus, we propose that Kin4 and Bud14 work in parallel and presence of both is critical for a robust SPOC arrest.

Interestingly, neither KIN4 nor BUD14 is required for spindle assembly checkpoint dependent metaphase arrest of cells, whereas Bfa1-Bub2 is (data not shown) (Pereira \& Schiebel, 2005). This suggest that the Kin4 and Bud14 become important to halt mitotic exit after APC/Cdc20 activation at the metaphase-anaphase transition. Anaphase onset also brings about the partial activation of Cdc14 by the FEAR pathway which primes MEN activation in several ways and Kin4 was shown to be dispensable for SPOC in cells lacking FEAR activity (Caydasi et al., 2017; Falk et al, 2016a; Scarfone et al, 2015). Consistently, Bud14 was also dispensable for SPOC in spo12 $\Delta$ cells that lack FEAR (data not shown). These data support that Kin4 and Bud14 work in parallel to keep Bfa1-Bub2 active in anaphase, to provide an arrest of anaphase cells prior to mitotic exit.

\section{Glc7-Bud14 promotes dephosphorylation of Bfa1}


The SPOC component Bfal is a highly phosphorylated protein in a cell cycle dependent manner. So far, Bfa1 has been shown to be the target of kinases Cdk1, Cdc5 and Kin4 (Caydasi et al., 2017; Geymonat et al, 2003; Hu et al., 2001; Pereira \& Schiebel, 2005). It is possible that other kinases may also phosphorylate Bfa1. There has been an ongoing curiosity for phosphatases that act on Bfa1. So far, Cdc14 was shown to counteract Cdk1 phosphorylation of Bfa1 (Caydasi et al., 2017) and PP2A-Cdc55 was shown to decrease Cdc5 dependent phosphorylation of Bfal (Baro et al, 2013). Our data that Bfal appears hyperphosphorylated in lte $1 \Delta$ bud14 $\Delta$ cells during an anaphase arrest that mimics SPOC activation indicate that Glc7-Bud14 promotes dephosphorylation of Bfa1. Consistently, inactivation of Glc7 by okadaic acid was able to promote hyperphosphorylation of Bfal in anaphase cell extracts. Furthermore, through an in vitro dephosphorylation assay we showed that Glc7-Bud14 is able to dephosphorylate the hyperphosphorylated form of Bfa1. We also observed an interaction between Bfal and Bud14 in yeast two hybrid assays, however we could not detect coimmunoprecipitation of Bfa1 and Bud14 (unpublished data) which might be an indication of the transient nature of this interaction.

Curiously, Bfa1-Bud14 interaction observed in the yeast two hybrid assay required presence of Bub2. Thus, Bud14 may recognize Bfa1-Bub2 as a complex, or the interaction between Bud14 and Bfa1 may require in vivo modifications of Bfal that occur only when bound to Bub2. It has been known that hyperphosphorylated forms of Bfal abolishes in the absence of Bub2 (Lee et al, 2001b). In addition, Bfa1 fails to localize to SPBs in the absence of Bub2 (Pereira et al., 2000). Furthermore, Bfa1 phosphorylation by Cdc5 takes place at SPBs (Maekawa et al., 2007; Pereira et al., 2000). These altogether are suggestive of a model in which Glc7-Bud14 may recognize specifically a phosphorylated form of Bfa1. We favor a speculative model where Glc7-Bud14 dephosphorylates Cdc5-phosphorylated Bfa1 specifically upon spindle misalignment. This model is also in concordance with our previous conclusion that Glc7-Bud14 works in a parallel pathway to Kin4. Removal of Cdc5 dependent phosphorylation of Bfa1 by Glc7-Bud14 and isolation of Bfa1 away from the inhibitory Cdc5 kinase activity by Kin 4 would concertedly reduce the levels of Cdc5 phosphorylated Bfa1 and thus work together to rapidly increase the levels of active Bfa1-Bub2 (Figure 8).

Kin4 phosphorylation of Bfal prevents Cdc5 phosphorylation of Bfa1 both during SPOC activation (i.e. anaphase arrest of lte $1 \Delta$ cells that mimics SPOC arrest) and during the metaphase arrest upon nocodazole treatment (Bertazzi et al., 2011; D'Aquino et al., 2005; 


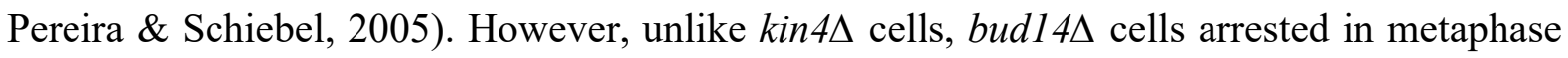
through nocodazole treatment did not have hyperphosphorylated Bfal (data not shown). This discrepancy between Kin4 and Glc7-Bud14 may indicate alternative scenarios: First, Glc7Bud14 may dephosphorylate sites other than those phosphorylated by Cdc5. Second, there may be redundant mechanisms of Bfal dephosphorylation at Cdc5 phosphorylation sites that especially dominate in metaphase. PP2A-Cdc55 was shown to counteract Bfa1 phosphorylation and cells lacking PP2A-Cdc55 activity had hyperphosphorylated Bfa1 in metaphase arrested cells (Baro et al., 2013). Therefore, one possibility is that PP2A-Cdc55 and Glc7-Bud14 may work redundantly to dephosphorylate Cdc5 phosphorylated Bfa1 at different stages of the cell cycle.

\section{Bud14 deletion causes an increase in SPB-bound levels of Bfa1-Bub2 and Tem1}

We observed that cells lacking BUD14 had more Bfa1, Bub2, and Tem1 localized at SPBs. This increase was more pronounced at the dSPB, making their localization more asymmetric. The asymmetry of Bfa1 at SPBs was shown to be dependent on Cdc5, as in the absence of Cdc5 activity Bfa1 localized more symmetrically to SPBs (Kim et al, 2012). Thus, presence of

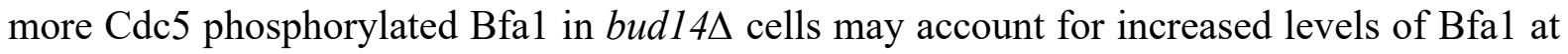
the dSPB and also Bub2 and Tem1 which bind SPBs in association with Bfa1. Alternatively, Glc7-Bud14 may have other targets that might increase Bfa1-Bub2 docking sites at the SPBs.

As suggested before (Scarfone et al., 2015; Valerio-Santiago \& Monje-Casas, 2011), increased Bfa1-Bub2 localization at SPBs can lead to increased MEN activity, as it also causes increased Tem1 association with SPBs. So, Bud14 may be inhibiting mitotic exit by two means: activation of Bfa1-Bub2 GAP complex through dephosphorylation and limiting the SPB-bound levels of Bfa1-Bub2, where the latter is most likely a consequence of the former.

\section{Where does Bud14-Glc7 dephosphorylate Bfa1?}

Bud cortex localization of Bud14 diminishes as the cells progress through anaphase both in cells with misaligned spindles and in cells with normally aligned spindles. Once disappeared from the bud cortex, Bud14 starts accumulating at the bud neck in cells with normal aligned spindles but not in cells with misaligned spindles. Thus, Bud14 is mostly cytoplasmic in cells with misaligned spindles, and Glc7-Bud14 may have access to Bfa1-Bub2 therein. Considering that Bfa1-Bub2 binding to SPBs is highly dynamic in cells with misaligned spindles and Bfa1- 
Bub2 is released from SPBs into the cytoplasm, Glc7-Bud14 may dephosphorylate Bfa1 in the cytoplasm.

Interestingly a truncated version of Bud14 that lacks the SH3 domain was also unable to inhibit mitotic exit. This truncated Bud14 is unable to localize at the bud cortex and also have reduced binding to Glc7 (Knaus et al., 2005). Thus, one possible explanation is that Bud14-SH3A may fail to inhibit mitotic exit due to its reduced association with Glc7. Alternatively, bud cortex localization of Bud14 may be important for Bud14 function in mitotic exit inhibition. Glc7Bud14 was implicated in microtubule cortex interactions. Although our observations that Bud14 bud cortex localization remains low during spindle misalignment may argue against the latter, Glc7-Bud14 function at the daughter cell cortex may be particularly important for SPOC mechanism in sensing spindle positioning defects. How spindle alignment is sensed, and this information activates SPOC still remain unknown. Data based on Kin4 activity on Bfa1 indicates that SPOC mechanism may sense microtubule-cortex interactions (Caydasi \& Pereira, 2009; Maekawa et al., 2007; Monje-Casas \& Amon, 2009; Pereira \& Schiebel, 2005). Due to their known function in regulating microtubule-cortex interactions (Knaus et al., 2005), Glc7-Bud14 constitutes a great candidate for sensing of such interactions. Considering that Glc7 (PP1) is a conserved phosphatase, similar mechanisms may be employed by higher eukaryotes. Future work will show whether Glc7-Bud14 may act as a sensor that translates the unattached microtubule-cortex interactions to the downstream SPOC machinery.

\section{Role of PP1 through the cell cycle}

PP1 has numerous functions in the control of the cell cycle (Holder et al, 2019; Kim et al, 2016; Moura \& Conde, 2019; Nasa \& Kettenbach, 2018). PP1, together with PP2A, is required for mitotic exit in animal cells by counteracting CDK activity (Wu et al, 2009). In human cells, PP1 also regulates centrosome splitting by antagonizing the Nek2 kinase (Meraldi \& Nigg, 2001). In addition, PP1 facilitates abscission by counteracting Plk1 mediated phosphorylation of the centrosomal protein CEP55 during late mitosis and thus promoting its midbody localization (Gao et al, 2018). In meiosis of Xenopus oocytes, PP1 regulates G2/M transition by partially activating Cdc25 (Perdiguero \& Nebreda, 2004). From yeast to mammals, PP1 is essential for silencing of the spindle assembly checkpoint by stabilizing kinetochore microtubule interactions by counteracting Aurora B and by potentially regulating recruitment of MCC to kinetochores (Kelly \& Funabiki, 2009; Kotwaliwale \& Biggins, 2006; Musacchio \& Salmon, 2007; Ruchaud et al, 2007). In this study, we show that budding yeast PP1, Glc7, 
inhibits mitotic exit upon anaphase spindle mispositioning. This function of PP1 seems to be opposite to the mitotic exit promoting role of PP1 reported in animal cells. The fact that mitotic exit is achieved by the Cdc14 phosphatase in budding yeast, instead of the PP1 and PP2 phosphatases (Manzano-Lopez \& Monje-Casas, 2020) is likely the reason for Glc7 gaining a different function after the anaphase onset during the narrow time window until exit from mitosis. 


\section{Materials Methods}

\section{Yeast methods, strains and growth}

All yeast strains used are isogenic with S288C and are listed in Table 1. Basic yeast methods and growth media were as described (Sherman, 1991). Carbon source is glucose unless otherwise stated. When necessary 2\% D-Raffinose, 3\% D(+)-Galactose was used instead of glucose. Yeast strains were grown at $30^{\circ} \mathrm{C}$ and in rich medium unless otherwise stated. Plasmid containing strains were grown in synthetic complete (SC) media lacking the appropriate auxotrophic nutrients. The temperature sensitive mutants and kar9D cells were maintained at $23{ }^{\circ} \mathrm{C}$. Cassette PCR-based gene editing method was used for chromosomal gene deletion and C-terminal or N-terminal tagging (Janke et al, 2004; Knop et al, 1999). To determine genetic interactions based on growth, mutant yeast strains bearing the wild type gene on a URA3-based plasmid (pRS316) were spotted on 5-Fluoroorotic acid (5FOA) plates. 5FOA plates negatively selects for the URA3-based plasmid and allows for observation of the growth phenotype in the absence of the corresponding plasmid. Most kar9 $9 \Delta$ cells were maintained complemented with KAR9 on URA3-based centromeric plasmid (pGW399), and stroke on 5FOA plates to induce plasmid lost shortly before experiments on SPOC analysis. The plasmids used in this study are listed in Table 2.

\section{Cell growth comparison on agar plates}

Yeast cultures were inoculated in appropriate growth conditions for $24-48$ hours. The $\mathrm{OD}_{600}$ of the cultures were adjusted to 1 and 10-fold serial dilutions were made using sterile PBS. $10 \mu 1$ of serial dilutions were spotted on appropriate agar plates and grown at appropriate temperatures for 1-3 days.

\section{Cell cycle synchronizations}

Cells were synchronized in G1 phase by treating log-phase cultures with $10 \mu \mathrm{g} / \mathrm{ml} \alpha$-factor (Sigma \#T6901) dissolved in DMSO and incubating for one and a half doubling time. For synchronization in metaphase without spindles, $15 \mu \mathrm{g} / \mathrm{ml}$ nocodazole (Sigma \#M1404) dissolved in DMSO were added to log-phase cultures and incubated for $\sim 2 \mathrm{~h}$. The arrest was confirmed by microscopy after fixing the cells with 70\% Ethanol and re-suspending in PBS containing $1 \mu \mathrm{g} / \mathrm{ml}$ 4',6-diamino-2-phenylindole (DAPI, Sigma). For nocodazole arrest from G1 synchronized yeast cultures, cells were first treated with $\alpha$-factor and released in 
nocodazole containing YPAD. For telophase arrest of Gal1-UPL-Tem1 bearing cells, after cultures were grown to log-phase in Raffinose-Galactose containing medium, cells were transferred into transferred into YPAD medium and grown for $\sim 3 \mathrm{~h}$ (until $>\% 90$ ) cells were arrested with large buds and 2 DAPI. For telophase arrest fom G1 arrested cells; first, logphase cultures of Gal1-UPL-Tem1 bearing cells grown in Raffinose/Galactose were treated with $\alpha$-factor. $30 \mathrm{~min}$ before G1 synchronization was completed, glucose was added to the culture to give $2 \%$ final concentration. Then cells were released from $\alpha$-factor in YPAD. The arrest was confirmed by microscopy after ethanol fixation of the cells and staining the nucleus with DAPI.

\section{Microscopy Methods}

All fluorescence microscopy methods were performed using Carl ZEISS Axio Observer 7 motorized inverted epifluorescence microscope equipped with Colibri 7 LED light source, Axiocam 702 Monochrome camera, 100X and 63X Plan Apochromat immersion oil objective lenses, Filter sets 95 (GFP/Cherry), 20 (Rhodamin), FITC and DAPI, and an XL incubation and climate chamber. For Kin4-GFP, GFP-Tubulin, Bud14-GFP analysis 63X objective was used. For analysis of Bfa1-GFP, Bub2-GFP, Tem1-GFP 100X objective was used.

For end-point analysis of samples, wet mounts of samples were prepared by sandwiching $2 \mu 1$ of culture between the coverslip-slide. Cells were either fixed using 70\% Ethanol and stained with DAPI or analyzed live. For time-lapse experiments, cells were prepared on glass bottom petri dishes (WVR 10810-054 Matsunami) as described (Caydasi \& Pereira, 2017). Briefly, the glass center of the petri dish was covered with $6 \%$ Concanavalin A (Canavalia ensiformis Jack Bean, type IV Sigma C2010-G). Excess Concanavalin A was washed out and $150 \mu 1$ of culture was pipetted on the dish followed by a $30 \mathrm{~min}$ incubation at $30{ }^{\circ} \mathrm{C}$. Then, cells were aspirated gently and cells there were not attached on the dish were washed out with pre-warmed fresh media. After the final wash, the dish was filled with media and taken to the microscope stage in preheated chamber 1 hour in advance the start of the time-lapse.

\section{SPOC functionality assays}

For end point analysis of SPOC functionality, log-phase $\operatorname{kar} 9 \Delta$ cells cultured at $23^{\circ} \mathrm{C}$ were incubated at $30^{\circ} \mathrm{C}$ for $3-5 \mathrm{~h}$ or log-phase $d y n 1 \Delta$ cells cultured at $30^{\circ} \mathrm{C}$ were incubated at $18{ }^{\circ} \mathrm{C}$ overnight. Cells were fixed using 70\% Ethanol, re-suspended in PBS containing $1 \mu \mathrm{g} / \mathrm{ml}$ DAPI and analyzed by microscopy. Cells bearing normal and misaligned nuclei, and cells with 
SPOC-deficient phenotypes including multinucleated cells were counted. Percentage of indicated phenotypes were plotted in Excel. For time lapse analysis of SPOC functionality, GFP-Tubulin bearing kar $9 \Delta$ cells were imaged every minute for $90 \mathrm{~min}$ at $30^{\circ} \mathrm{C} .10 \mathrm{z}$-stacks of $0.4 \mu \mathrm{m}$ thickness were taken at each time point. Anaphase duration of cells with correct and misaligned spindles was calculated as the time from the start of fast spindle elongation (metaphase-to-anaphase transition) until spindle breakdown (Caydasi et al., 2010b; Straight et al, 1997). Dot plots were prepared in GraphPad Prism 8.0.1(GraphPad, La Jolla, CA).

\section{Localization based fluorescence image quantifications}

For signal intensity quantification of Bfa1-GFP, Bub2-GFP and Tem1-GFP, we took still images of live cells bearing SPC42-eqFP and mCherry-TUB1 as a mitotic marker. Each still image consisted of $13 \mathrm{z}$-stacks of $0.3 \mu \mathrm{m}$ thickness. Z-stacks of the images were sum-projected, and mean fluorescence intensities were measured using Image J (NIH) software and corrected as described (Caydasi et al., 2012). Briefly, a $0.577 \mu \mathrm{m}^{2}$ (42 pixels) box was selected around the spindle pole body under inspection (ROI, region of interest) and the mean fluorescence intensity of the GFP signal was measured. Background fluorescence intensity was determined by measuring an area inside the cytoplasm of respective cell, near to the region of interest. The correction was done by subtracting the mean fluorescence intensity of the background from the mean fluorescence intensity of the ROI.

To detect the behavior of asymmetric localization of Bfa1 at SPBs, ratio of the corrected signal intensities (as described above) at the SPBs were calculated. For cells with normally aligned spindles, the signal intensity at the dSPB was divided to the signal intensity at the mSPB. For cells with misaligned spindles, the SPB with the greater signal was considered as dSPB.

Statistical results and graphs were computed and plotted by using Prism 8.0.1 (GraphPad, La Jolla, CA). Two-tailed t-test were applied to compare the statistical significance of the signal intensity measurements in a pair-wise manner. Chi-square test were applied for comparison of Bud14-GFP cortex localization.

\section{Yeast Two Hybrid Assay}

Yeast Two Hybrid analysis was performed as described (Meitinger et al, 2014). Briefly, indicated genes cloned into pMM5 (LexA-myc fusion, HIS autotrophy marker) and pMM6 (Gal4-HA fusion, LEU2 autotrophy marker) were transformed into the yeast strain SGY37 that 
contains a chromosomally integrated LexA(op)-LacZ reporter for activation of the Bgalactosidase gene. Transformants were selected on SC-His-Leu agar plates, grown in SC-HisLeu media until stationary phase, diluted to $1 \mathrm{OD}_{600}$ and $10 \mu 1$ of each were spotted on SC-HisLeu agar plates. Cells were grown for 48 hours and plates were overlaid with $0.4 \%$ soft-agar solution containing $0.4 \mathrm{mg} / \mathrm{ml} \mathrm{X-Gal,} 0.1 \% \mathrm{SDS}, 10 \mathrm{mM} \mathrm{KCl}$ and $1 \mathrm{mM} \mathrm{MgCl}$. Blue color formation was monitored.

\section{Protein Methods}

Total yeast protein precipitation, sample preparation, and Western blotting following Laemmli SDS-PAGE were performed as previously described (Meitinger et al, 2016). Total cell native protein extracts were prepared by lysis of cells using acid washed glass beads (Sigma) in a cooling bead beater homogenizer (Analytik Jena, SpeedMill Plus). Primary antibodies were Mouse-anti-HA (Gift from Gislene Pereira), Rabbit anti-Clb2 (Gift from Gislene Pereira), Rabbit-anti-Tubulin (Abcam EPR13799) Rabbit anti-TAP (Thermofisher scientific CAB1001). Secondary antibodies were Goat-anti-rabbit (Advansta \#R-05062-500) or Goatanti-mouse (Advansta \#R-05071-500) horse radish peroxidase (HRP) conjugated secondary antibodies.

\section{Phosphatase Assay}

Glc7-TAP and Bud14-TAP were enriched on IgG Sepharose beads (GE Healthcare BioScience) according to manufacturer's recommendations. In addition, ESM356-1 (a strain without TAP tag) was used as a no-tag control. Briefly, cell pellets of logarithmically growing cultures were lysed using acid washed glass beads (Sigma) and a cooling bead beater homogenizer (Analytik Jena, SpeedMill Plus) in a lysis buffer containing 50mM Hepes pH:7.5, $150 \mathrm{mM} \mathrm{NaCl}, 1 \mathrm{mM}$ EDTA , \%1 SDS, 1mM DTT, 2mM PMSF and complete Protease Inhibitor Coctail (Roche). The lysate was cleared by centrifugation at $10000 \mathrm{rpm}$ at $+4{ }^{\circ} \mathrm{C}$ and the supernatant was incubated with IgG beads for $2 \mathrm{~h}$ at $4{ }^{\circ} \mathrm{C}$. Beads were washed with ice cold wash buffer containing 50mM Hepes $\mathrm{pH}: 7.5,150 \mathrm{mM} \mathrm{NaCl}, 0.1 \mathrm{mM}$ EDTA, $\% 0.1$ SDS, $\% 0.025$ Tween $20,1 \mathrm{mM}$ DTT and were immediately used for the phosphatase reaction as a phosphatase source.

Bfa1-3HA was purified from BFA1-3HA kin4 Gall -UPL-TEM1 cells arrested in anaphase. For this, log-phase culture grown in Raffinose/Galactose containing rich medium were transferred into YPAD medium. After $>90 \%$ of the cell arrest was achieved, cell pellets were 
lysed using acid washed glass beads in bead beater. Lysis buffer composition was: $50 \mathrm{mM}$ Hepes pH:7.5, 150mM NaCl, 5\% Glycerol, 1mM EDTA, 1\% NP-40, 160mM $\beta-$ Glycerophosphate, $2 \mathrm{mM} \mathrm{NaVO}_{3}, 100 \mathrm{mM} \mathrm{NaF}, 2 \mathrm{mM}$ PMSF, 4mM Benzamidine and complete Protease Inhibitor Coctail (Roche). After clearing the cell lysate by centrifugation at 10000 rpm at $+4{ }^{\circ} \mathrm{C}$, the cell extract was incubated with anti-HA magnetic beads (Thermofisher, Pierce $^{\mathrm{TM}}$ ) for $2 \mathrm{~h}$ at $4{ }^{\circ} \mathrm{C}$. After the incubation the beads were washed in 50mM Hepes pH: 7.5, $150 \mathrm{mM} \mathrm{NaCl}, \% 1 \mathrm{NP}-40, \% 5$ Glycerol, $1 \mathrm{mM}$ EDTA and eluted from beads under basic elution conditions according to manufacturer's protocol. Briefly, beads were incubated with $50 \mathrm{mM}$ $\mathrm{NaOH}$ for 5 minutes and the eluate was immediately neutralized by $300 \mathrm{mM}$ Tris $\mathrm{pH}: 8.5$. Next, the eluate was applied on PD MiniTrap G-25 Sephadex (GE Healthcare) columns equilibrated with a buffer containing 50mM Hepes $\mathrm{pH}$ : 7.5, 100mM NaCl. Buffer exchange was performed according to manufacturer's spin protocol.

In vitro phosphatase reaction was performed using the IgG-beads that contained Bud14-TAP or Glc7-TAP or the IgG-beads that was incubated with the cell extract of the ESM356-1 control. Bfa1-3HA that was prepared as explained above was added as the substrate. Phosphatase reaction buffer composition was $100 \mathrm{mM} \mathrm{NaCl}, 50 \mathrm{mM}$ Hepes $\mathrm{pH}$ : 7.5, 2mM DTT, $\% 0.025$ Tween, $2 \mathrm{mM} \mathrm{MnCl}_{2}$. Okadaic acid (Abcam) was also added to the indicated reactions to $2 \mathrm{nM}$ or $1.5 \mu \mathrm{M}$ final concentrations to inhibit PP2 or both PP1 and PP2 respectively. After reaction was incubated at $30{ }^{\circ} \mathrm{C}$ for $1 \mathrm{~h}, 5 \mathrm{x}$ sample buffer was added immediately into the reaction tubes, samples were boiled at $95^{\circ} \mathrm{C}$ for $5 \mathrm{~min}$ and analyzed by western blotting.

For analysis of the effect of Glc7 activity on Bfa1-3HA mobility on SDS-PAGE, BFA1-3HA kin4 $\triangle$ Gal1 -UPL-TEM1 cells arrested in anaphase were lysed using acid washed glass beads in bead beater. Lysis buffer composition was: 50mM Hepes pH:7.5, 150mM NaCl, 5\% Glycerol, 1mM EDTA, 1\% NP-40, 2mM PMSF, 4mM Benzamidine and complete Protease Inhibitor Coctail (Roche). Okadaic acid was also added to the lysis buffer in indicated tubes to $2 \mathrm{nM}$ or $1.5 \mu \mathrm{M}$ final concentrations to inhibit PP2 or both PP1 and PP2 respectively. Then the cell lysate was cleared by centrifugation at $10000 \mathrm{rpm}$ at $+4{ }^{\circ} \mathrm{C}, 5 \mathrm{X}$ sample buffer was added to the extracts, boiled at $95^{\circ} \mathrm{C}$ for 5 min and analyzed by western blotting 


\section{Acknowledgements}

This work was supported by TÜBITAK Grant No. 117C041, EMBO installation Grant No. 3918 and ICGEP installation Grant No. CRP/TUR17-04_EC. CD was funded by Koç University, HK and IK were funded by TÜBITAK Grant No. $118 Z 979$ and SNE was funded by TÜBITAK Grant No. $117 Z 232$ granted to AKC. AKC was funded by MSCA Individual Fellowship No. 796599-COHEMEX. We are grateful to Gislene Pereira (COS, Heidelberg), Elmar Schiebel (ZMBH, Heidelberg) and Matthias Peter (ETH, Zürich) and Michael Knop (ZMBH, Heidelberg) for sharing reagents, strains and plasmids.

\section{Author Contributions}

HK, DK, CD, IK and SNE designed and performed the experiments. AKC acquired funding, designed experiments, supervised HK, DK, CD, IK and SNE, and wrote the manuscript.

\section{Conflict of Interest}

The authors declare that they have no conflict of interest. 


\section{Figure Legends}

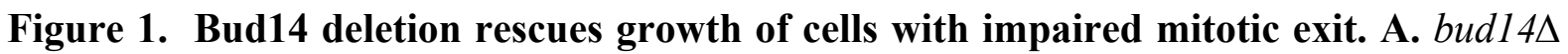

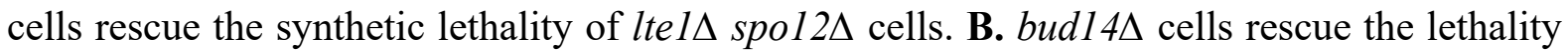
of lte $1 \Delta$ cells at $18{ }^{\circ} \mathrm{C}$. C. bud14A rescues lethality of MEN-ts mutants. Serial dilutions of indicated strains were spotted on indicated plates and grown at given temperatures. 5-FOA plates negatively selects for the URA3-based plasmids (pRS316 containing the LTE1 in A and $\mathrm{B}$, pRS316 containing the wild type gene copy of the corresponding MEN mutant in C). Thus, only cells that have lost these plasmids can grow on 5-FOA plates where genetic interactions can be observed.

Figure 2. bud14 $\triangle$ cells are SPOC deficient. A-B. End-point analysis of SPOC integrity of indicated yeast strains in $\operatorname{kar} 9 \Delta$ (A) and $d y n 1 \Delta$ (B) background. Cells were fixed with ethanol and stained with DAPI. Cells with normally aligned nuclei (white columns), mispositioned nuclei (grey columns) and multi nucleated cells that failed to correctly position their spindle before mitotic exit (black columns) were counted by microscopy and their percentages were plotted. Graphs are average of three independent experiments. A minimum of 100 cells were counted from each strain in each experiment. Error bars show standard deviation. C. Single cell analysis of SPOC integrity in indicated strains. Duration of anaphase in cells with misaligned and normally aligned spindles were calculated as explained in the text and plotted as dot-plots. Cartoon on the right illustrates how anaphase duration was calculated. Data points in red indicate the cells in which the spindle did not break down during the time lapse movie. In this case, plotted values are the time duration during which these cells were observed in anaphase through the time lapse movie. Consequently, the actual anaphase duration is greater than the value plotted in red. This fact is emphasized in the red part of the y-axis, indicated above the red dashed line, with addition of the ">" symbol before the y-axis values. Green dash line indicates the mean value of the anaphase duration in cells with normally aligned spindles. $P$ values calculated using students' t-test are indicated on the dot plot. $n$ : sample size.

Figure 3. GIc7-Bud14 interaction and SH3 domain plays a role in mitotic exit inhibitory role of Bud14. A. Serial dilutions of indicated strains bearing URA3-based empty plasmid (not indicated on figure) or BUD14-containing URA3-based plasmids (BUD14 and bud14-F379A) were spotted on indicated plates and grown at indicated temperatures B. Serial dilutions of indicated strains bearing LTE1 on URA3-based pRS316 plasmid were spotted on 5-FOA and SC plates and grown at indicated temperatures. 5-FOA negatively selects for $U R A 3$ containing 
plasmids, thus cells lose their pRS316-LTE1 plasmids on 5-FOA plates and genetic interactions can be observed on this plate. C-E. End-point analysis of SPOC integrity of indicated strains. Cells were fixed with ethanol and stained with DAPI. Cells with normally positioned nuclei (white columns), mispositioned nuclei (grey columns) and multi nucleated cells that failed to correctly position their spindle before mitotic exit (black columns) were counted by microscopy and their percentages were plotted. Graphs are average of three independent experiments. A minimum of 100 cells were counted from each strain in each experiment. Error bars show standard deviation. F. Serial dilutions of indicated strains with URA3-based empty plasmid (not indicated on figure) or with BUD14- containing URA3-based plasmids (BUD14, bud14-SH3 or bud14-5A) were spotted on SC-URA and grown at indicated temperatures. G. SPOC integrity assay of indicated strains, performed as in C-E. H-I. Colony growth assays performed as in B.

Figure 4. Bud14 interacts with Bfa1 in yeast two hybrid system. A-B. SGY37 with or without KIN4 or BUB2 was co-transformed with pMM6 (contains Gal4 Activation Domain) and pMM5 (contains LexA DNA Binding Domain) bearing indicated genes. Empty plasmids served as a control for any self-activation. Kel1 served as a positive control. $10 \mu 1$ of 1 OD cell culture dropped on selective agar plates were grown for two days before overlay. Blue color formation was monitored as an indication of protein-protein interaction. B. Same as in A

Figure 5. More Bfa1 localizes to SPBs in the absence of BUD14. A. Bfa1-GFP signal intensity quantifications at the SPBs of BFA1-GFP mCherry-TUB1 or BFA1-GFP mCherryTUB1 bud14A cells with normal aligned anaphase spindles were plotted on the right. Black and grey lines in the dot plots are the mean value and standard deviation respectively. Representative still images of cells were shown on the left. B. Bfal-GFP signal intensities at the dSPB were plotted in BUD14 and bud14 $\Delta$ cells bearing empty plasmid (blue and red), as well as bud14 $\Delta$ cells bearing a BUD14 containing plasmid (green). C. Analysis of Bfa1-GFP asymmetry at the SPBs of $\operatorname{kar} 9 \Delta, \operatorname{kar} 9 \Delta \operatorname{kin} 4 \Delta$ and $\operatorname{kar} 9 \Delta$ bud $14 \Delta$ cells with correctly aligned and misaligned anaphase spindles. Box and Whisker plot shows the ratio of Bfa1-GFP signal intensities at the SPB1 and SPB2, where SPB1 always corresponds to SPB with the greater Bfa1-GFP signal. The box represents first and third quartile while the whiskers show 10-90 percentile of the data. The horizontal line in the box indicate the median of the data. Representative still images of cells are shown on the right. Pairwise comparisons of intensities 
among indicated strains were assessed using Students' t-test. p-values were shown on the graph. n: sample size. Scale bar: $2 \mu \mathrm{m}$.

Figure 6. Glc7-Bud14 promotes Bfa1 dephosphorylation in anaphase. A-B. Bfa1-3HA Gal1-UPL-Tem1 containing strains were released from alpha factor imposed G1 arrest $(\mathrm{t}=0)$ into an alpha factor free medium supplemented with glucose to achieve Tem1 depletion and samples were collected at indicated time points. Cell cycle progression was monitored by budding index and DAPI plots by microscopy (B) as well as Clb2 levels by western blotting (A). Bfa1-3HA mobility shift was analyzed via western blotting (A). A lower and a higher exposed film was shown for better visualization of the up and down shifted Bfa1-3HA protein ratios. Arrows indicate hyperphosphorylated forms of Bfa1-3HA (A). Protein samples of each strain at 75, 90 and 120 minutes were also loaded side-by-side for better comparison of Bfal mobility (A). C. Cell lysates of BFA1-3HA Gal1-UPL-TEM1 kin4 $\Delta$ cells were prepared in the absence of phosphatase inhibitors or in the presence of indicated concentrations of okadaic acid. Bfa1-3HA mobility shift was detected using anti-HA antibodies. Ponceau S serves as loading control. D. In vitro phosphatase assay of immunoprecipitated Glc7-TAP or Bud14TAP incubated with Bfa1-3HA purified from BFA1-3HA Gal1-UPL-TEM1 kin4 $\Delta$ cells in the presence or absence of indicated concentrations of okadaic acid. Glc7-TAP and Bud14-TAP levels were detected using anti-TAP antibodies. Bfa1-3HA was detected using anti-HA antibodies. Green and red arrows indicate slow migrating and fast migrating forms of Bfa1$3 \mathrm{HA}$ respectively.

\section{Figure 7. Localization of Bud14 in cells with normal and misaligned anaphase spindles.}

A. Percentage of anaphase cells with Bud14-GFP cortex enrichment at the bud cortex of kar9D cells with correctly and incorrectly positioned anaphase spindles. $m$ Cherry-TUB1 was used as a spindle marker. Chi-square test was performed for pairwise comparison of percentage of cells with Bud14-GFP cortex enrichment $(\mathrm{p}<0.0001)$. Representative still images for cells with or without Bud14-GFP cortex enrichment were shown on the left. Scale bar: $2 \mu \mathrm{m}$. B. Selected frames from time-lapse series of BUD14-GFP $m$ Cherry-TUB1 cells. Two cells, one of which has a normally aligned spindle (outlined with orange dashed line) and the other has a misaligned anaphase spindle (outlined with yellow dashed line) are shown. Asterisk indicate the time of anaphase entry for both cells. Arrow indicates spindle breakage in the cell with correctly positioned spindle. 
Figure 8. Model for SPOC activation. In cells with a correctly positioned anaphase spindle (cartoon on the left), Bfal binds stably to the SPB that migrates to the daughter cell (dSPB) and disappears from the SPB that stays in the mother (mSPB). Cdc5 localized to the outer plaque of the SPBs in anaphase (Botchkarev et al, 2017) has access to Bfal in the dSPB, phosphorylates Bfa1 therein, and inactivates the GAP activity of the Bfa1-Bub2 complex (black line). Bfa1-Bub2 at dSPB recruits more Tem1 to the dSPB and MEN is activated. In cells with a mispositioned anaphase spindles, Bfa1-SPB binding becomes more dynamic (red dashed line). Kin4 localizes to both spindle poles, phosphorylates Bfa1 (orange line), and Kin4 phosphorylated Bfa1 is rapidly released from the dSPB (red dashed line) together with Bub2. Also in the absence of Kin4, Bfa1-Bub2 starts dissociating from SPBs upon spindle mispositioning but at a very slow rate (Caydasi \& Pereira, 2009). Bfa1 released from the SPB into the cytoplasm can be dephosphorylated by the Glc7/Bud14, thus restoring Bfa1-Bub2 GAP activity and also by preventing association of Bfal with the SPBs. 


\section{Supplementary Figure Legends}

Figure S1. Bud14 does not influence Kin4 function. A. Serial dilutions of indicated strains were spotted on Glucose containing (YPD) and Galactose containing (YP Raf/Gal) agar plates. Gal1-Kin4 overexpression is induced on Galactose containing plates B. Logarithmic growing cultures bearing Kin4-GFP and Spc42-eqFP were treated with nocodazole for 2 hours and Kin4 SPB and cortex localization was analyzed by microscopy. rts1 $1 \Delta$ cells were used as a control in which Kin4 fails to localize to SPBs and cortex. Graph is an average of three independent experiments. Error bars are standard deviation. At least 100 cells were counted from each sample in each experiment. C. Logarithmic growing Kin4-6HA cultures bearing the indicated gene deletions were treated with nocodazole for 3 hours to obtain $>90 \%$ cell population arrested in metaphase with a single DAPI staining and large buds. Kin4 mobility shift was analyzed by western blotting using ant-HA antibodies. $r t s 1 \Delta$ served as a control for hyperphosphorylated Kin4.

Figure S2. Bfa1, Bub2 and Tem1 localization in bud14 $\Delta$ cells during anaphase and metaphase. A-B. Bub2-GFP and Tem1-GFP signal intensity quantifications at the SPBs of BFA1-GFP $m$ Cherry-TUB1 or BFA1-GFP mCherry-TUB1 bud14A cells with normal aligned anaphase spindles were plotted in B. Black and grey lines in the dot plots are the mean value and standard deviation respectively. Representative still images of cells were shown in A. C. Bfa1-GFP, Bub2-GFP and Tem1-GFP signal intensities at the SPBs of cells with metaphase spindles (spindle length $=1,5-2 \mu \mathrm{m}$ ). Graph is plotted as described in B. D. Analysis of Bfa1-

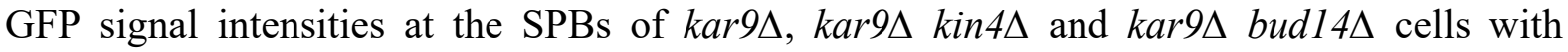
correctly aligned and misaligned anaphase spindles. The graph was plotted as in B. Pairwise comparisons of intensities among indicated strains were assessed using Students' t-test. pvalues were shown on the graph. n: sample size. Scale bar: $2 \mu \mathrm{m}$.

Figure S3. Bfa1-GFP localization during spindle misalignment. Selected frames from timelapse series of BFA1-GFP SPC42-eqFP mCherry-TUB1 bearing kar9D (A), kar9D bud14A (B) and $\operatorname{kar} 9 \Delta \operatorname{kin} 4 \Delta(\mathrm{C})$ gene deletions. Cell boundaries are outlined with a dashed line. Blue arrows indicate the SPBs. Time points from the beginning of the time lapse is indicated on the frames. Scale bar: $2 \mu \mathrm{m}$.

Figure S4. Logarithmic growing cultures of KIN4-GFP SPC42-eqFP $m$ Cherry-TUB1 bearing cells with indicated gene deletions were imaged live. Kin4 localization at the cortex and SPBs 
were analyzed in anaphase cells (spindle length $>5$ ). Images of representative cells and one representative graph out of 3 experiments was shown. A minimum of 100 cells were counted from each sample. 


\section{Tables}

Table 1. Yeast strains used in this study.

\begin{tabular}{|c|c|c|}
\hline $\begin{array}{l}\text { Strain } \\
\text { Name }\end{array}$ & Description & Reference \\
\hline ESM356 & MATa ura3-52 leu2 $\Delta 1$ his $3 \Delta 200$ trp $1 \Delta 63$ & (Pereira \& Schiebel, 2001) \\
\hline YPH499 & $\begin{array}{l}\text { MATa ura3-52 lys2-801 ade2-101 trp1 } 1 \Delta 63 \text { his } 3 \Delta 200 \\
\text { leu2A1 }\end{array}$ & (Sikorski \& Hieter, 1989) \\
\hline $\begin{array}{l}\text { SGY37- } \\
\text { VIII,3 }\end{array}$ & $\begin{array}{l}\text { MATa leu2 his3 trp1 ADE2 ura3-52::URA3-lexA-op- } \\
\text { LacZ }\end{array}$ & (Geissler et al, 1996) \\
\hline GPY491 & YPH499 cdc14-2 pRS316- CDC14 & (Caydasi et al., 2017) \\
\hline ESM2285 & YPH499 mob1-67 pRS316-MOB1 & (Caydasi et al., 2017) \\
\hline JOY79 & YPH499 cdc5-10 pRS316-CDC5 & (Caydasi et al., 2017) \\
\hline ESM2283 & YPH499 dbf2-2 pRS316-DBF2 & (Caydasi et al., 2017) \\
\hline ESM2282 & YPH499 cdc15-1 pRS316-CDC15 & (Caydasi et al., 2017) \\
\hline FAY145 & $\begin{array}{l}\text { MATa ura3-52 his } 3 \Delta 200 \text { leu2 } 21 \text { lte } 1 \Delta:: \text { kanMX6 } \\
\text { pRS316-LTE1 }\end{array}$ & (Bertazzi et al., 2011) \\
\hline AKY2526 & $\begin{array}{l}\text { FAY145 lte1 } 1:: k a n M X 6 \text { pRS316-LTE1 } \\
\text { spo12A::natNT2 }\end{array}$ & (Caydasi et al., 2017) \\
\hline AKY2916 & 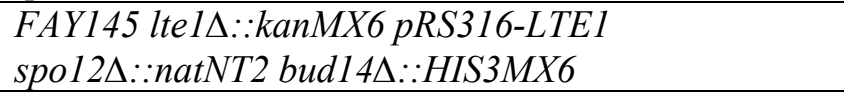 & This study \\
\hline DKY069 & 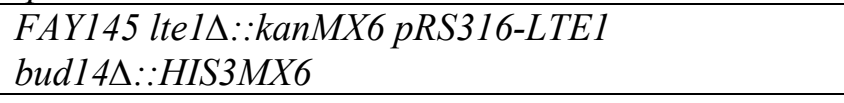 & This study \\
\hline DKY057 & YPH499 cdc14-2 pRS316-CDC14 bud144::klTRP3 & This study \\
\hline DKY058 & YPH499 mob1-67 pRS316-MOB1 bud144::klTRP3 & This study \\
\hline DKY060 & YPH499 dbf2-2 pRS316-DBF2 bud14A::klTRP3 & This study \\
\hline DKY061 & YPH499 cdc15-1 pRS316-CDC15 bud144::klTRP3 & This study \\
\hline AKY260 & ESM356 kar9D::HIS3MX6 pRS316-KAR9 & (Caydasi et al., 2017) \\
\hline AKY315 & $\begin{array}{l}\text { ESM356 kar9A::HIS3MX6 pRS316-KAR9 } \\
\text { bfa1 }:: k l T R P 1\end{array}$ & (Caydasi et al., 2017) \\
\hline AKY321 & 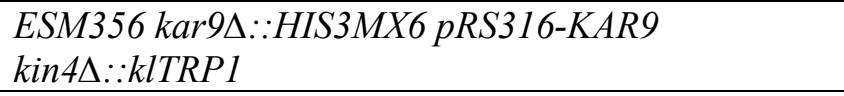 & (Caydasi et al., 2017) \\
\hline AKY2917 & $\begin{array}{l}\text { YPH499 GFP-Tub1-URA3 dyn1D::klTRP1 } \\
\text { bud14A::HIS3MX6 }\end{array}$ & This study \\
\hline AKY2918 & 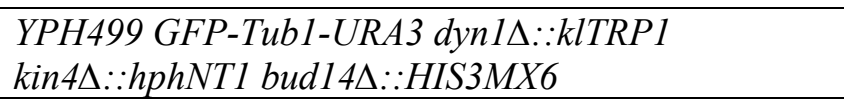 & This study \\
\hline SHM562 & YPH499 GFP-Tub1-URA3 dyn1A::klTRP1 & (Pereira \& Schiebel, 2005) \\
\hline ESM2156 & 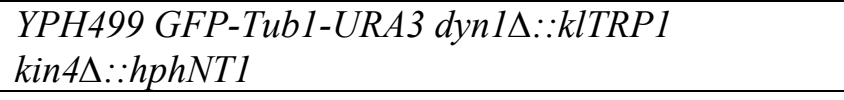 & (Pereira \& Schiebel, 2005) \\
\hline AKY346 & $\begin{array}{l}\text { YPH499 kar9D::klTRP1 pRS316-KAR9 GFP-Tub1- } \\
\text { ADE2 }\end{array}$ & (Caydasi et al., 2010b) \\
\hline AKY351 & $\begin{array}{l}\text { YPH499 kar9A::klTRP1 pRS316-KAR9 } \\
\text { kin } 4 \Delta:: H I S 3 M X 6 \text { GFP-Tub1-ADE2 }\end{array}$ & (Caydasi et al., 2010b) \\
\hline SEY032 & $\begin{array}{l}\text { YPH499 kar9D::klTRP1 pRS316-KAR9 GFP-Tub1- } \\
\text { ADE2 bud14D::HIS3MX6 }\end{array}$ & This study \\
\hline AKY4068 & 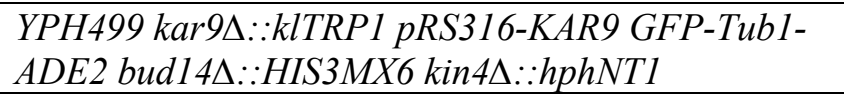 & This study \\
\hline DKY131 & 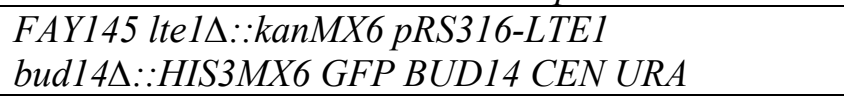 & This study \\
\hline
\end{tabular}




\begin{tabular}{|c|c|c|}
\hline DKY132 & ESM356 bud14A::klTRP GFP BUD14 CEN URA & This study \\
\hline DKY135 & 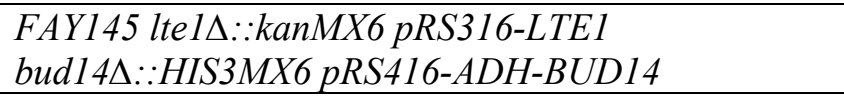 & This study \\
\hline DKY137 & $\begin{array}{l}\text { FAY145 lte } 1 \Delta:: k a n M X 6 \text { pRS316-LTE1 } \\
\text { bud14A::HIS3MX6 pRS416-ADH-BUD14 [F379A] }\end{array}$ & This study \\
\hline PAY704 & $\begin{array}{l}\text { W303 MATa ade2-1 his3-11,15 leu2-3,112 ura3-1 } \\
\text { can1-100 ssd1-d2 glc7::LEU2 trp1-1::GLC7::TRP1 }\end{array}$ & (Andrews \& Stark, 2000) \\
\hline PAY701 & $\begin{array}{l}\text { W303 MATa ade2-1 his3-11,15 leu2-3,112 ura3-1 } \\
\text { can1-100 ssd1-d2 glc7::LEU2 trp1-1::glc7-12::TRP1 }\end{array}$ & (Andrews \& Stark, 2000) \\
\hline DKY074 & $\begin{array}{l}\text { PAY701 glc7::LEU2 trp1-1::glc7-12::TRP1 } \\
\text { lte1 } \because:: H I S 3 M X 6\end{array}$ & This study \\
\hline DKY075 & $\begin{array}{l}\text { PAY704 glc7::LEU2 trp } 1-1: \because G L C 7: \because T R P 1 \\
\text { lte1 } \triangle:: H I S 3 M X 6\end{array}$ & This study \\
\hline DKY078 & 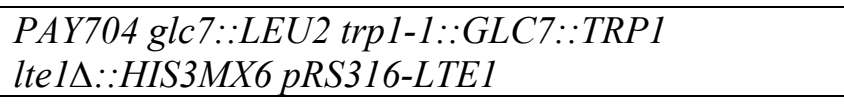 & This study \\
\hline DKY079 & 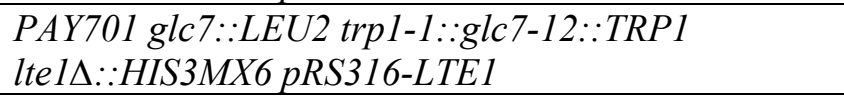 & This study \\
\hline DKY080 & 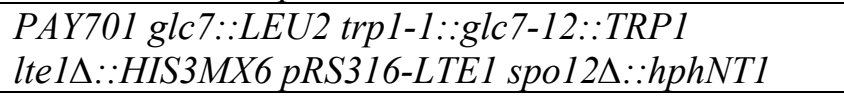 & This study \\
\hline DKY145 & 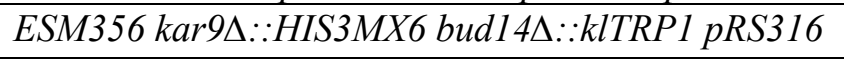 & This study \\
\hline DKY147 & $\begin{array}{l}\text { ESM356 kar9A ::HIS3MX6 bud14A::klTRP1 pRS416- } \\
\text { ADH-BUD14 }\end{array}$ & This study \\
\hline DKY149 & 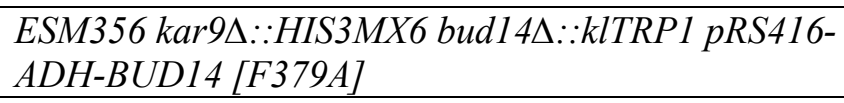 & This study \\
\hline AKY1533 & ESM356 leu2::LEU2-pGal1-KIN4 & This study \\
\hline AKY1574 & ESM356 leu2::LEU2-pGal1-KIN4 bub2A::hphNT1 & This study \\
\hline AKY4001 & ESM356 leu2::LEU2-pGal1-KIN4 bud14A::klTRP1 & This study \\
\hline GPY1033 & ESM356-1 KIN4-GFP-his3MX6 Spc42-eqFP-natNT2 & (Pereira \& Schiebel, 2005) \\
\hline DGY004 & $\begin{array}{l}\text { ESM356 KIN4-GFP-HIS3MX6 Spc42-eqFP-natNT2 } \\
\text { bud144::klTRP1 }\end{array}$ & This study \\
\hline DKY063 & $\begin{array}{l}\text { ESM356 KIN4-GFP-HIS3MX6 Spc42-eqFP611- } \\
\text { natNT2 bud14A::klTRP1 }\end{array}$ & This study \\
\hline AKY404 & $\begin{array}{l}\text { ESM356 KIN4-GFP-HIS3MX6 Spc42-eqFP-natNT2 } \\
\text { rts1A::klTRP1 }\end{array}$ & (Caydasi et al., 2010b) \\
\hline ESM2326 & ESM356 KIN4-6HA-hphNT1 & (Caydasi et al., 2010b) \\
\hline AKY415 & ESM356 KIN4-6HA-hphNT1 rts1D::klTRP1 & (Caydasi et al., 2010b) \\
\hline DGY001 & ESM356 KIN4-6HA-hphNT1 bud14A::klTRP1 & This study \\
\hline DKY118 & $\begin{array}{l}\text { ESM356 GAL1-UPL-TEM1::kITRP1 BFA1-3HA- } \\
\text { hphNT1 lte1A::natNT2 }\end{array}$ & This study \\
\hline DKY125 & $\begin{array}{l}\text { ESM356 GAL1-UPL-TEM1::kITRP1 BFA1-3HA- } \\
\text { hphNT1 kin4D::natNT2 bud14A::HIS3MX6 }\end{array}$ & This study \\
\hline DKY126 & $\begin{array}{l}\text { ESM356 GAL1-UPL-TEM1::kITRP1 BFA1-3HA- } \\
\text { hphNT1 lte1D::natNT2 bud14A::HIS3MX6 }\end{array}$ & This study \\
\hline DKY167 & 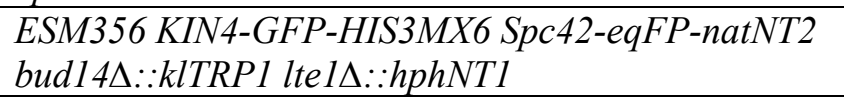 & This study \\
\hline AKY038 & $\begin{array}{l}\text { ESM356 Bfa1-GFP-kanMX6 Spc42-eqFP- hphNT1 } \\
\text { mCherry-Tub1-URA3 }\end{array}$ & This study \\
\hline AKY4011 & $\begin{array}{l}\text { ESM356 Bfal-GFP-kanMX6 Spc42-eqFP-hphNT1 } \\
\text { bud14D::klTRP1 mCherry-Tub1-URA3 }\end{array}$ & This study \\
\hline AKY4007 & $\begin{array}{l}\text { ESM356 Bub2-GFP-kanMX6 Spc42-eqFP-hphNT1 } \\
\text { mCherry-Tub1-URA3 }\end{array}$ & This study \\
\hline
\end{tabular}




\begin{tabular}{|c|c|c|}
\hline AKY4009 & $\begin{array}{l}\text { ESM356 Bub2-GFP-kanMX6 Spc42-eqFP-hphNT1 } \\
\text { bud14A::klTRP1 mCherry-Tub1-URA3 }\end{array}$ & This study \\
\hline AKY4013 & $\begin{array}{l}\text { ESM356 Tem1-GFP-kanMX6 Spc42-eqFP-hphNT1 } \\
\text { mCherry-Tub1-URA3 }\end{array}$ & This study \\
\hline AKY4008 & $\begin{array}{l}\text { ESM356 Tem 1-GFP-kanMX6 Spc42-eqFP-hphNT1 } \\
\text { bud14A::HIS3MX6 mCherry-Tub1-URA3 }\end{array}$ & This study \\
\hline HKY114 & $\begin{array}{l}\text { ESM356 Bfa1-GFP-kanMX6 Spc42-eqFP-hphNT1 } \\
\text { mCherry-Tub1-LEU2 pRS416 }\end{array}$ & This study \\
\hline HKY115 & $\begin{array}{l}\text { ESM356 Bfal-GFP-kanMX6 Spc42-eqFP-hphNT1 } \\
\text { bud14A::klTRP1 mCherry-Tub1-LEU2 pRS416 }\end{array}$ & This study \\
\hline HKY116 & $\begin{array}{l}\text { ESM356 Bfa1-GFP-kanMX6 Spc42-eqFP-hphNT1 } \\
\text { bud144::klTRP1 mCherry-Tub1-LEU2 pRS416- } \\
\text { BUD14 }\end{array}$ & This study \\
\hline AKY043 & $\begin{array}{l}\text { ESM356 BFA1-GFP-kanMX6 Spc42-eqFP-hphNT1 } \\
\text { kar9D::klTRP1 pRS316-KAR9 }\end{array}$ & (Caydasi \& Pereira, 2009) \\
\hline BKY032 & $\begin{array}{l}\text { ESM356 BFA1-GFP-kanMX6 Spc42-eqFP hphNT1 } \\
\text { kar9A::klTRP1 pRS316-KAR9 kin4A::HIS3MX6 }\end{array}$ & (Caydasi \& Pereira, 2009) \\
\hline DKY081 & $\begin{array}{l}\text { ESM356 BFA1-GFP-kanMX6 Spc42-eqFP hphNT1 } \\
\text { kar9A::klTRP1 pRS316-KAR9 bud14A::HIS3MX6 }\end{array}$ & This study \\
\hline IKY075 & SGY37-VIII, 3 kin4 $4:: k l T R P 1$ & This study \\
\hline DKY113 & SGY37-VIII,3 bub2A::hphNT1 & This study \\
\hline AKY4070 & $\begin{array}{l}\text { ESM356-1 SPC42-EQFP611-KanMX6 bud14-GFP- } \\
\text { hisMX6 mCherry-TUB1-URA3 kar9D::klTRP1 }\end{array}$ & This study \\
\hline GYBY002 & $\begin{array}{l}\text { YPH499 Asst1::HisG. YAS7-1 BUD14-Tev-4ProA- } \\
\text { KanMX6 }\end{array}$ & This study \\
\hline GYBY004 & $\begin{array}{l}\text { YPH499 Dsst1::HisG. YAS7-1 GLC7-Tev-4ProA- } \\
\text { KanMX6 }\end{array}$ & This study \\
\hline
\end{tabular}

Table 2. Plasmids used in this study

\begin{tabular}{|c|c|c|}
\hline $\begin{array}{l}\text { Plasmid } \\
\text { Name }\end{array}$ & Description & Reference \\
\hline pRS316 & $\begin{array}{l}\text { URA3-dependent CEN-based yeast-E.coli shuffle } \\
\text { plasmid. AmpR. }\end{array}$ & (Sikorski \& Hieter, 1989) \\
\hline pWS103-1 & pRS304-Gall-UPL-TEM1 & (Shou et al., 1999) \\
\hline pMK60 & $\begin{array}{l}\text { pRS416-endogenous BUD14-promoter-GFP- } \\
\text { BUD14 }\end{array}$ & (Knaus et al., 2005) \\
\hline pMK125 & $p R S 416$ ADH-BUD14 & (Knaus et al., 2005) \\
\hline pMK131 & pRS416 ADH-BUD14 ${ }^{F 379 A}$ & (Knaus et al., 2005) \\
\hline pSM903-4 & pRS316-LTE1 & (Hofken, 2002) \\
\hline pGW399-1 & pRS316-KAR9 & (Hofken, 2002) \\
\hline pDKY001 & $\begin{array}{l}\text { pRS416-endogenous BUD14-promoter- GFP- } \\
\text { BUD14 } 4^{5 A} \text { (135A 137A 138A 139A 140A) }\end{array}$ & This Study \\
\hline pDKY003 & $\begin{array}{l}\text { pRS416-endogenous BUD14-promoter- GFP- } \\
\text { BUD14 }\end{array}$ & This Study \\
\hline pMM5 & p423-Gal1-lexA-Myc & (Geissler et al., 1996) \\
\hline pMM6 & p425-Gal1-Gal4-HA. & (Geissler et al., 1996) \\
\hline pHA69-1 & pMM5-BUD14 & Gift from G. Pereira \\
\hline
\end{tabular}




\begin{tabular}{|l|l|l|}
\hline pHA132-2 & $p M M 6-K I N 4$ & Gift from G. Pereira \\
\hline pCL2-1 & $p M M 6-B U B 2$ & (Hofken \& Schiebel, 2004) \\
\hline pHA70-1 & $p M M 6-B U D 14$ & Gift from G. Pereira \\
\hline pCL4a-3 & $p M M 6-B F A 1$ & (Hofken \& Schiebel, 2004) \\
\hline pTH221 & pMM6-KEL & (Hofken \& Schiebel, 2004) \\
\hline pAFS125 & GFP-TUB1-URA3 containing integration plasmid. & (Straight et al., 1997) \\
\hline pBK067-1 & pRS305 $\triangle$ KpnI-mCherry-TUB1. & (Caydasi et al., 2014) \\
\hline pGW399 & pRS316-KAR9 & (Caydasi et al., 2010b) \\
\hline
\end{tabular}

\section{References}

Adames NR, Cooper JA (2000) Microtubule interactions with the cell cortex causing nuclear movements in Saccharomyces cerevisiae. J Cell Biol 149: 863-874

Adames NR, Oberle JR, Cooper JA (2001) The surveillance mechanism of the spindle position checkpoint in yeast. J Cell Biol 153: 159-168

Andrews PD, Stark MJ (2000) Type 1 protein phosphatase is required for maintenance of cell wall integrity, morphogenesis and cell cycle progression in Saccharomyces cerevisiae. Journal of cell science 113 ( Pt 3): 507-520

Asakawa K, Yoshida S, Otake F, Toh-e A (2001) A novel functional domain of Cdc15 kinase is required for its interaction with Tem1 GTPase in Saccharomyces cerevisiae. Genetics 157: $1437-1450$

Bardin AJ, Visintin R, Amon A (2000) A mechanism for coupling exit from mitosis to partitioning of the nucleus. Cell 102: 21-31

Baro B, Queralt E, Monje-Casas F (2017) Regulation of Mitotic Exit in Saccharomyces cerevisiae. Methods in molecular biology 1505: 3-17

Baro B, Rodriguez-Rodriguez JA, Calabria I, Hernaez ML, Gil C, Queralt E (2013) Dual Regulation of the mitotic exit network (MEN) by PP2A-Cdc55 phosphatase. PLoS genetics 9: e1003966

Beach DL, Thibodeaux J, Maddox P, Yeh E, Bloom K (2000) The role of the proteins Kar9 and Myo2 in orienting the mitotic spindle of budding yeast. Curr Biol 10: 1497-1506

Bertazzi DT, Kurtulmus B, Pereira G (2011) The cortical protein Lte1 promotes mitotic exit by inhibiting the spindle position checkpoint kinase Kin4. J Cell Biol 193: 1033-1048 
Bialojan C, Takai A (1988) Inhibitory effect of a marine-sponge toxin, okadaic acid, on protein phosphatases. Specificity and kinetics. Biochem J 256: 283-290

Bloecher A, Venturi GM, Tatchell K (2000) Anaphase spindle position is monitored by the BUB2 checkpoint. Nat Cell Biol 2: 556-558

Botchkarev VV, Jr., Garabedian MV, Lemos B, Paulissen E, Haber JE (2017) The budding yeast Polo-like kinase localizes to distinct populations at centrosomes during mitosis. Molecular biology of the cell 28: 1011-1020

Campbell IW, Zhou X, Amon A (2020) Spindle pole bodies function as signal amplifiers in the Mitotic Exit Network. Molecular biology of the cell 31: 906-916

Caydasi AK, Ibrahim B, Pereira G (2010a) Monitoring spindle orientation: Spindle position checkpoint in charge. Cell division 5: 28

Caydasi AK, Khmelinskii A, Duenas-Sanchez R, Kurtulmus B, Knop M, Pereira G (2017) Temporal and compartment-specific signals coordinate mitotic exit with spindle position. Nature communications 8: 14129

Caydasi AK, Kurtulmus B, Orrico MI, Hofmann A, Ibrahim B, Pereira G (2010b) Elm1 kinase activates the spindle position checkpoint kinase Kin4. J Cell Biol 190: 975-989

Caydasi AK, Lohel M, Grunert G, Dittrich P, Pereira G, Ibrahim B (2012) A dynamical model of the spindle position checkpoint. Molecular systems biology 8: 582

Caydasi AK, Micoogullari Y, Kurtulmus B, Palani S, Pereira G (2014) The 14-3-3 protein Bmh1 functions in the spindle position checkpoint by breaking Bfal asymmetry at yeast centrosomes. Molecular biology of the cell 25: 2143-2151

Caydasi AK, Pereira G (2009) Spindle alignment regulates the dynamic association of checkpoint proteins with yeast spindle pole bodies. Dev Cell 16: 146-156

Caydasi AK, Pereira G (2012) SPOC alert--when chromosomes get the wrong direction. Experimental cell research 318: 1421-1427

Caydasi AK, Pereira G (2017) Evaluation of the Dynamicity of Mitotic Exit Network and Spindle Position Checkpoint Components on Spindle Pole Bodies by Fluorescence Recovery After Photobleaching (FRAP). Methods in molecular biology 1505: 167-182

Cenamor R, Jimenez J, Cid VJ, Nombela C, Sanchez M (1999) The budding yeast Cdc15 localizes to the spindle pole body in a cell-cycle-dependent manner. Mol Cell Biol Res Commun 2: $178-184$

Cheng J, Turkel N, Hemati N, Fuller MT, Hunt AJ, Yamashita YM (2008) Centrosome misorientation reduces stem cell division during ageing. Nature 456: 599-604 
Cheng YL, Chen RH (2010) The AAA-ATPase Cdc48 and cofactor Shp1 promote chromosome bi-orientation by balancing Aurora B activity. Journal of cell science 123: 20252034

Chesarone M, Gould CJ, Moseley JB, Goode BL (2009) Displacement of formins from growing barbed ends by bud14 is critical for actin cable architecture and function. Dev Cell 16: 292-302

Cohen P, Klumpp S, Schelling DL (1989a) An improved procedure for identifying and quantitating protein phosphatases in mammalian tissues. FEBS Lett 250: 596-600

Cohen P, Schelling DL, Stark MJ (1989b) Remarkable similarities between yeast and mammalian protein phosphatases. FEBS Lett 250: 601-606

Cullen PJ, Sprague GF, Jr. (2002) The Glc7p-interacting protein Bud14p attenuates polarized growth, pheromone response, and filamentous growth in Saccharomyces cerevisiae. Eukaryot Cell 1: 884-894

D'Aquino KE, Monje-Casas F, Paulson J, Reiser V, Charles GM, Lai L, Shokat KM, Amon A (2005) The protein kinase Kin4 inhibits exit from mitosis in response to spindle position defects. Mol Cell 19: 223-234

Eshel D, Urrestarazu LA, Vissers S, Jauniaux JC, van Vliet-Reedijk JC, Planta RJ, Gibbons IR (1993) Cytoplasmic dynein is required for normal nuclear segregation in yeast. Proc Natl Acad Sci U S A 90: 11172-11176

Eskin JA, Rankova A, Johnston AB, Alioto SL, Goode BL (2016) Common forminregulating sequences in Smy1 and Bud14 are required for the control of actin cable assembly in vivo. Molecular biology of the cell 27: 828-837

Falk JE, Campbell IW, Joyce K, Whalen J, Seshan A, Amon A (2016a) LTE1 promotes exit from mitosis by multiple mechanisms. Molecular biology of the cell 27: 3991-4001

Falk JE, Chan LY, Amon A (2011) Lte1 promotes mitotic exit by controlling the localization of the spindle position checkpoint kinase Kin4. Proc Natl Acad Sci U S A 108: 12584-12590

Falk JE, Tsuchiya D, Verdaasdonk J, Lacefield S, Bloom K, Amon A (2016b) Spatial signals link exit from mitosis to spindle position. eLife 5

Gao K, Zhang Y, Shi Q, Zhang J, Zhang L, Sun H, Jiao D, Zhao X, Tao H, Wei Y et al (2018) iASPP-PP1 complex is required for cytokinetic abscission by controlling CEP55 dephosphorylation. Cell Death Dis 9: 528

Geissler S, Pereira G, Spang A, Knop M, Soues S, Kilmartin J, Schiebel E (1996) The spindle pole body component Spc98p interacts with the gamma-tubulin-like Tub4p of 
Saccharomyces cerevisiae at the sites of microtubule attachment. The EMBO journal 15: 38993911

Geymonat M, Spanos A, Jensen S, Sedgwick SG (2010) Phosphorylation of Lte1 by Cdk prevents polarized growth during mitotic arrest in S. cerevisiae. J Cell Biol 191: 1097-1112

Geymonat M, Spanos A, Smith SJ, Wheatley E, Rittinger K, Johnston LH, Sedgwick SG (2002) Control of mitotic exit in budding yeast. In vitro regulation of Tem1 GTPase by Bub2 and Bfa1. J Biol Chem 277: 28439-28445

Geymonat M, Spanos A, Walker PA, Johnston LH, Sedgwick SG (2003) In vitro regulation of budding yeast Bfa1/Bub2 GAP activity by Cdc5. J Biol Chem 278: 14591-14594

Gould CJ, Chesarone-Cataldo M, Alioto SL, Salin B, Sagot I, Goode BL (2014) Saccharomyces cerevisiae Kelch proteins and Bud14 protein form a stable 520-kDa formin regulatory complex that controls actin cable assembly and cell morphogenesis. $J$ Biol Chem 289: $18290-18301$

Gruneberg U, Campbell K, Simpson C, Grindlay J, Schiebel E (2000) Nud1p links astral microtubule organization and the control of exit from mitosis. The EMBO journal 19: 64756488

Hofken T, Schiebel E (2002) A role for cell polarity proteins in mitotic exit. The EMBO journal 21: 4851-4862

Hofken T, Schiebel E (2004) Novel regulation of mitotic exit by the Cdc42 effectors Gic1 and Gic2. J Cell Biol 164: 219-231

Holder J, Poser E, Barr FA (2019) Getting out of mitosis: spatial and temporal control of mitotic exit and cytokinesis by PP1 and PP2A. FEBS Lett 593: 2908-2924

Hu F, Wang Y, Liu D, Li Y, Qin J, Elledge SJ (2001) Regulation of the Bub2/Bfa1 GAP complex by Cdc5 and cell cycle checkpoints. Cell 107: 655-665

Janke C, Magiera MM, Rathfelder N, Taxis C, Reber S, Maekawa H, Moreno-Borchart A, Doenges G, Schwob E, Schiebel E et al (2004) A versatile toolbox for PCR-based tagging of yeast genes: new fluorescent proteins, more markers and promoter substitution cassettes. Yeast 21: 947-962

Jaspersen SL, Charles JF, Tinker-Kulberg RL, Morgan DO (1998) A late mitotic regulatory network controlling cyclin destruction in Saccharomyces cerevisiae. Molecular biology of the cell 9: 2803-2817

Kelly AE, Funabiki H (2009) Correcting aberrant kinetochore microtubule attachments: an Aurora B-centric view. Curr Opin Cell Biol 21: 51-58 
Kim HS, Fernandes G, Lee CW (2016) Protein Phosphatases Involved in Regulating Mitosis: Facts and Hypotheses. Mol Cells 39: 654-662

Kim J, Luo G, Bahk YY, Song K (2012) Cdc5-dependent asymmetric localization of bfa1 fine-tunes timely mitotic exit. PLoS genetics 8: e1002450

Knaus M, Cameroni E, Pedruzzi I, Tatchell K, De Virgilio C, Peter M (2005) The Bud14p-Glc7p complex functions as a cortical regulator of dynein in budding yeast. The EMBO journal 24: 3000-3011

Knop M, Siegers K, Pereira G, Zachariae W, Winsor B, Nasmyth K, Schiebel E (1999) Epitope tagging of yeast genes using a PCR-based strategy: more tags and improved practical routines. Yeast 15: 963-972 1105-1108

Kotwaliwale C, Biggins S (2006) Microtubule capture: a concerted effort. Cell 127:

Krogan NJ, Cagney G, Yu H, Zhong G, Guo X, Ignatchenko A, Li J, Pu S, Datta N, Tikuisis AP et al (2006) Global landscape of protein complexes in the yeast Saccharomyces cerevisiae. Nature 440: 637-643

Lee SE, Frenz LM, Wells NJ, Johnson AL, Johnston LH (2001a) Order of function of the budding-yeast mitotic exit-network proteins Tem1, Cdc15, Mob1, Dbf2, and Cdc5. Curr Biol 11: 784-788

Lee SE, Jensen S, Frenz LM, Johnson AL, Fesquet D, Johnston LH (2001b) The Bub2dependent mitotic pathway in yeast acts every cell cycle and regulates cytokinesis. Journal of cell science 114: 2345-2354

Lenssen E, James N, Pedruzzi I, Dubouloz F, Cameroni E, Bisig R, Maillet L, Werner M, Roosen J, Petrovic K et al (2005) The Ccr4-Not complex independently controls both Msn2-dependent transcriptional activation--via a newly identified Glc7/Bud14 type I protein phosphatase module--and TFIID promoter distribution. Mol Cell Biol 25: 488-498

Li YY, Yeh E, Hays T, Bloom K (1993) Disruption of mitotic spindle orientation in a yeast dynein mutant. Proc Natl Acad Sci U S A 90: 10096-10100

Maekawa H, Priest C, Lechner J, Pereira G, Schiebel E (2007) The yeast centrosome translates the positional information of the anaphase spindle into a cell cycle signal. J Cell Biol 179: $423-436$

Manzano-Lopez J, Monje-Casas F (2020) The Multiple Roles of the Cdc14 Phosphatase in Cell Cycle Control. Int J Mol Sci 21 
Meitinger F, Khmelinskii A, Morlot S, Kurtulmus B, Palani S, Andres-Pons A, Hub B, Knop M, Charvin G, Pereira G (2014) A memory system of negative polarity cues prevents replicative aging. Cell 159: 1056-1069

Meitinger F, Palani S, Pereira G (2016) Detection of Phosphorylation Status of Cytokinetic Components. Methods in molecular biology 1369: 219-237

Meraldi P, Nigg EA (2001) Centrosome cohesion is regulated by a balance of kinase and phosphatase activities. Journal of cell science 114: 3749-3757

Miller RK, Rose MD (1998) Kar9p is a novel cortical protein required for cytoplasmic microtubule orientation in yeast. J Cell Biol 140: 377-390

Molk JN, Schuyler SC, Liu JY, Evans JG, Salmon ED, Pellman D, Bloom K (2004) The differential roles of budding yeast Tem $1 p, C d c 15 p$, and Bub2p protein dynamics in mitotic exit. Molecular biology of the cell 15: 1519-1532

Monje-Casas F, Amon A (2009) Cell polarity determinants establish asymmetry in MEN signaling. Dev Cell 16: 132-145

Morishita T, Mitsuzawa H, Nakafuku M, Nakamura S, Hattori S, Anraku Y (1995) Requirement of Saccharomyces cerevisiae Ras for completion of mitosis. Science 270: 12131215 9

Moura M, Conde C (2019) Phosphatases in Mitosis: Roles and Regulation. Biomolecules

Musacchio A, Salmon ED (2007) The spindle-assembly checkpoint in space and time. Nature reviews Molecular cell biology 8: 379-393

Nasa I, Kettenbach AN (2018) Coordination of Protein Kinase and Phosphoprotein Phosphatase Activities in Mitosis. Front Cell Dev Biol 6: 30

Neller J, Dunkler A, Rosler R, Johnsson N (2015) A protein complex containing Epo1p anchors the cortical endoplasmic reticulum to the yeast bud tip. $J$ Cell Biol 208: 71-87

O'Connell CB, Wang YL (2000) Mammalian spindle orientation and position respond to changes in cell shape in a dynein-dependent fashion. Molecular biology of the cell 11: 17651774

Perdiguero E, Nebreda AR (2004) Regulation of Cdc25C activity during the meiotic G2/M transition. Cell Cycle 3: 733-737

Pereira G, Hofken T, Grindlay J, Manson C, Schiebel E (2000) The Bub2p spindle checkpoint links nuclear migration with mitotic exit. Mol Cell 6: 1-10 
Pereira G, Schiebel E (2001) The role of the yeast spindle pole body and the mammalian centrosome in regulating late mitotic events. Curr Opin Cell Biol 13: $762-769$

Pereira G, Schiebel E (2005) Kin4 kinase delays mitotic exit in response to spindle alignment defects. Mol Cell 19: 209-221

Pereira G, Yamashita YM (2011) Fly meets yeast: checking the correct orientation of cell division. Trends Cell Biol

Rock JM, Amon A (2009) The FEAR network. Curr Biol 19: R1063-1068

Ruchaud S, Carmena M, Earnshaw WC (2007) Chromosomal passengers: conducting cell division. Nature reviews Molecular cell biology 8: 798-812

Scarfone I, Piatti S (2015) Coupling spindle position with mitotic exit in budding yeast: The multifaceted role of the small GTPase Tem1. Small GTPases 6: 196-201

Scarfone I, Venturetti M, Hotz M, Lengefeld J, Barral Y, Piatti S (2015) Asymmetry of the budding yeast Tem1 GTPase at spindle poles is required for spindle positioning but not for mitotic exit. PLoS genetics 11: e1004938

Seshan A, Bardin AJ, Amon A (2002) Control of Lte1 localization by cell polarity determinants and Cdc14. Curr Biol 12: 2098-2110

Sherman F (1991) Getting started with yeast. Methods Enzymol 194: 3-21

Shirayama M, Matsui Y, Tanaka K, Toh-e A (1994a) Isolation of a CDC25 family gene, MSI2/LTE1, as a multicopy suppressor of ira1. Yeast 10: 451-461

Shirayama M, Matsui Y, Toh EA (1994b) The yeast TEM1 gene, which encodes a GTPbinding protein, is involved in termination of M phase. Mol Cell Biol 14: 7476-7482

Shou W, Seol JH, Shevchenko A, Baskerville C, Moazed D, Chen ZW, Jang J, Charbonneau H, Deshaies RJ (1999) Exit from mitosis is triggered by Tem1-dependent release of the protein phosphatase Cdc14 from nucleolar RENT complex. Cell 97: 233-244

Sikorski RS, Hieter P (1989) A system of shuttle vectors and yeast host strains designed for efficient manipulation of DNA in Saccharomyces cerevisiae. Genetics 122: 19-27

Siller KH, Doe CQ (2009) Spindle orientation during asymmetric cell division. Nat Cell Biol 11: 365-374

Stegmeier F, Visintin R, Amon A (2002) Separase, polo kinase, the kinetochore protein Slk19, and Spo 12 function in a network that controls Cdc14 localization during early anaphase. Cell 108: 207-220 
Straight AF, Marshall WF, Sedat JW, Murray AW (1997) Mitosis in living budding yeast: anaphase A but no metaphase plate. Science 277: 574-578

Valerio-Santiago M, Monje-Casas F (2011) Tem1 localization to the spindle pole bodies is essential for mitotic exit and impairs spindle checkpoint function. J Cell Biol 192: 599-614

Visintin R, Amon A (2001) Regulation of the mitotic exit protein kinases Cdc15 and Dbf2. Molecular biology of the cell 12: 2961-2974

Weiss EL (2012) Mitotic Exit and Separation of Mother and Daughter Cells. Genetics 192: $1165-1202$

Wu JQ, Guo JY, Tang W, Yang CS, Freel CD, Chen C, Nairn AC, Kornbluth S (2009) PP1-mediated dephosphorylation of phosphoproteins at mitotic exit is controlled by inhibitor1 and PP1 phosphorylation. Nat Cell Biol 11: 644-651

Yeh E, Skibbens RV, Cheng JW, Salmon ED, Bloom K (1995) Spindle dynamics and cell cycle regulation of dynein in the budding yeast, Saccharomyces cerevisiae. J Cell Biol 130: $687-700$ 


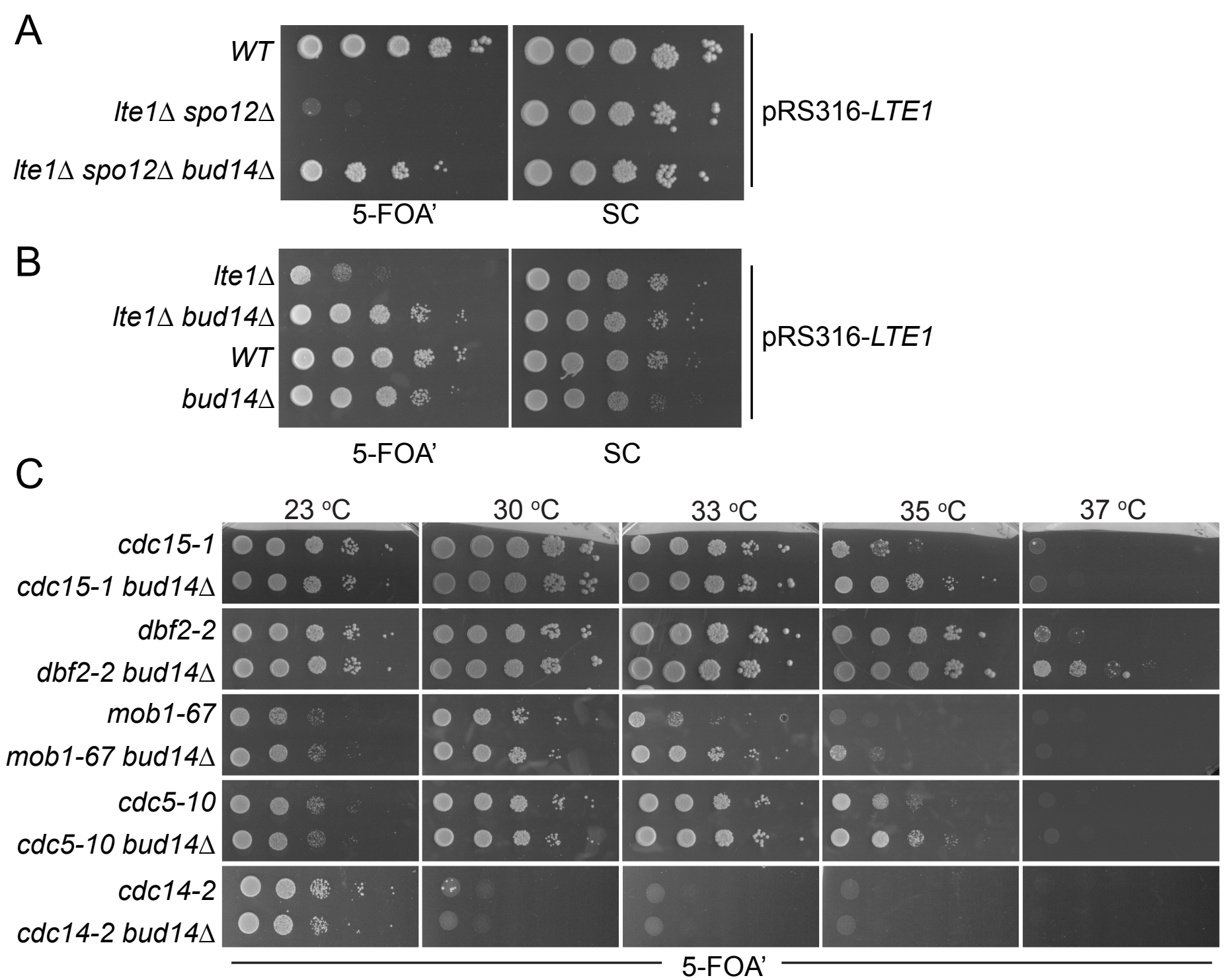


Figure 2

A

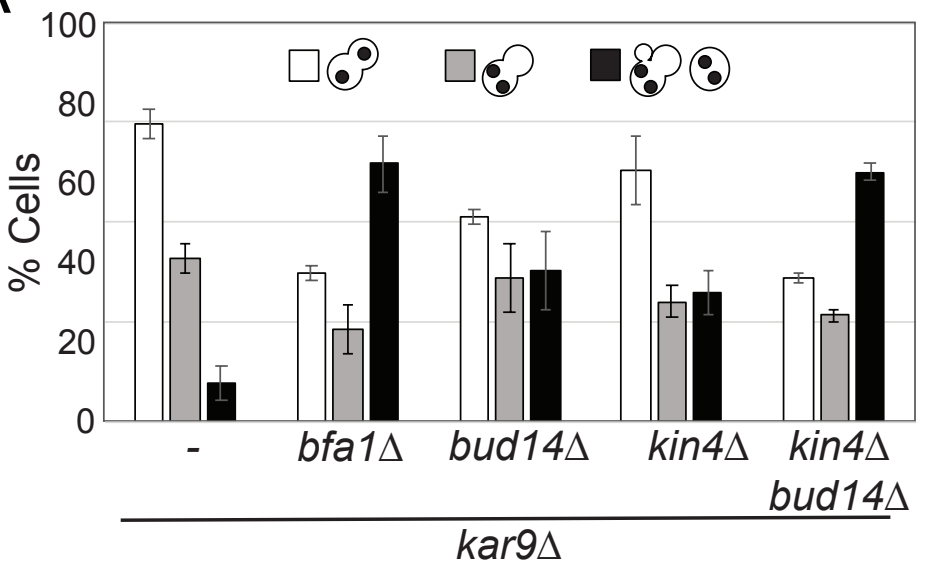

B

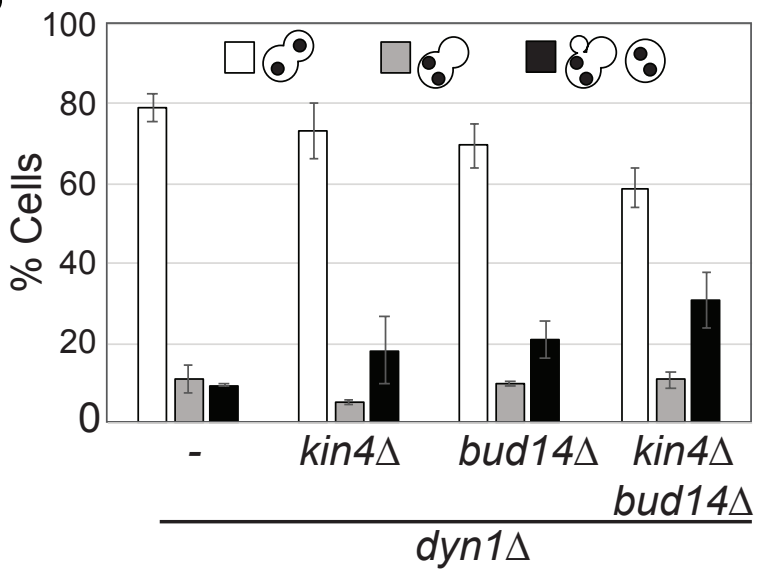

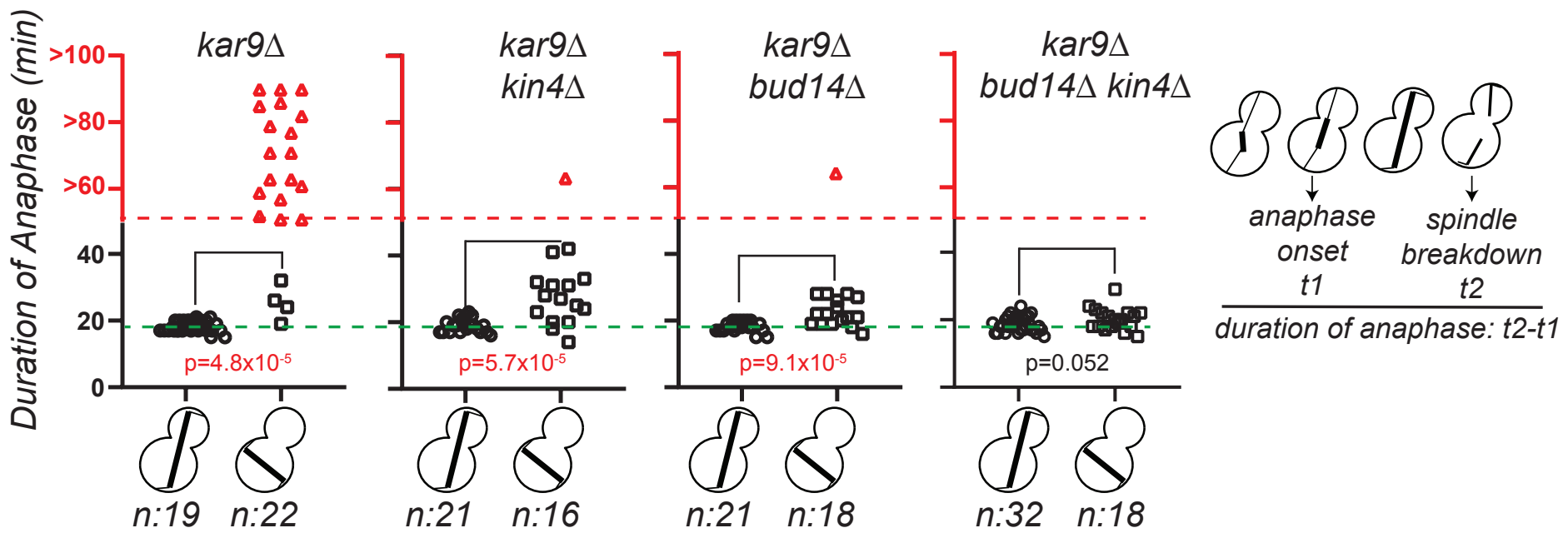


bioRxiv preprint doi: https://doi.org/10.1101/2020.08.30.273946; this version posted November 19,2020 . The copyright holder for this preprint (which was not certified by peer review) is the author/funder, who has granted bioRxiv a license to display the preprint in Figure 3 perpetuity. It is made available under aCC-BY-NC-ND 4.0 International license.
A

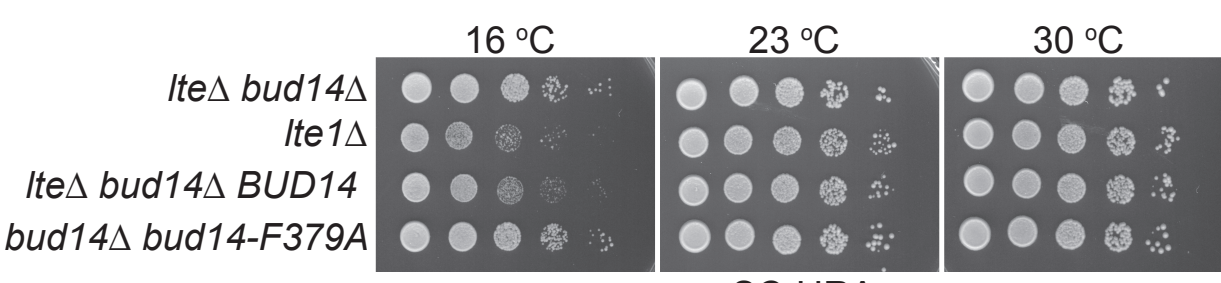
SC-URA

B
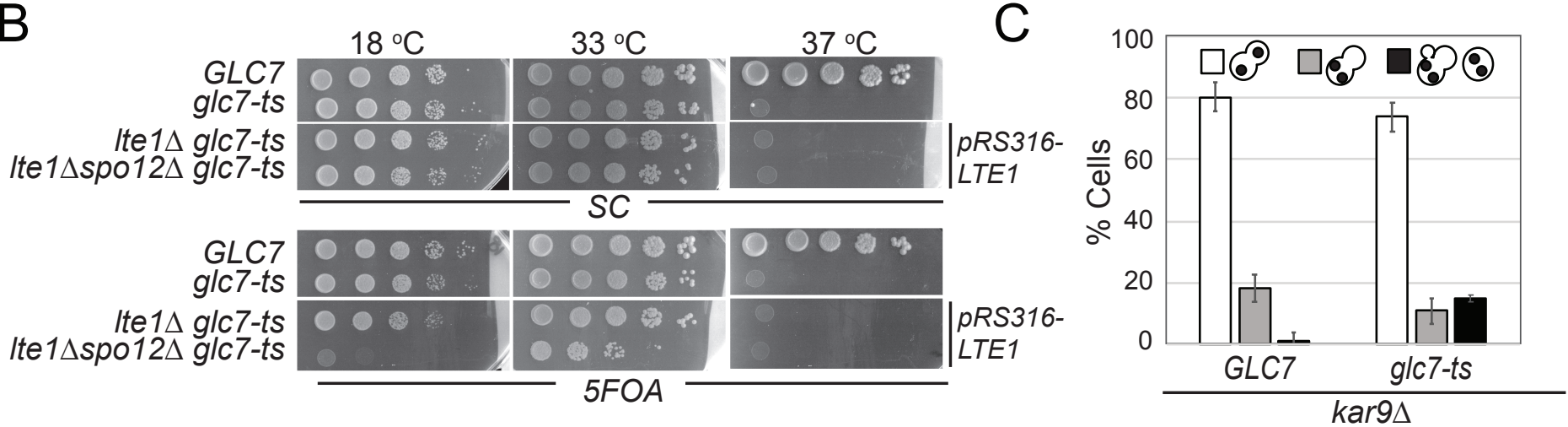

$\mathrm{D}$

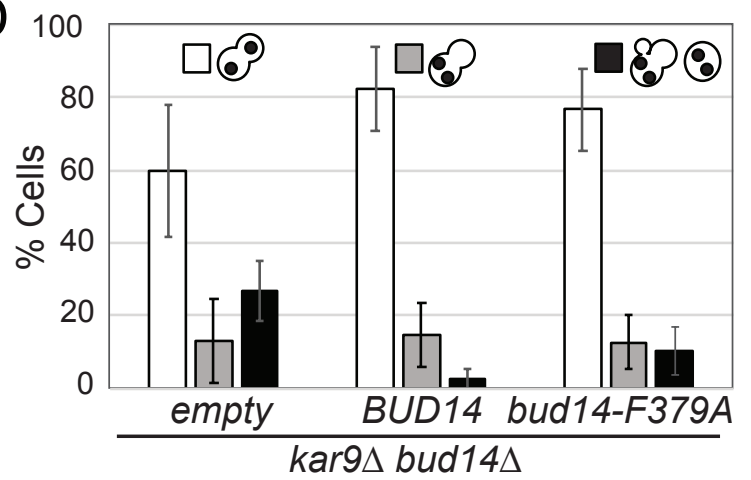

$\mathrm{E}$

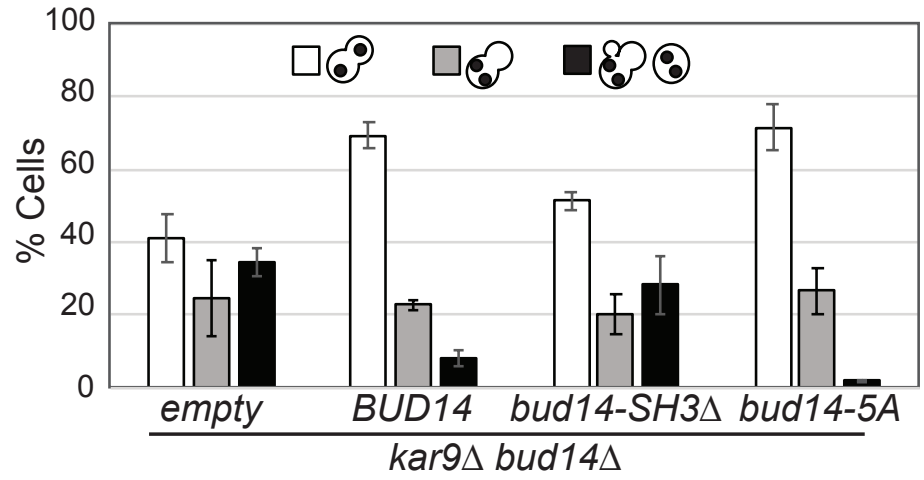

$\mathrm{F}$

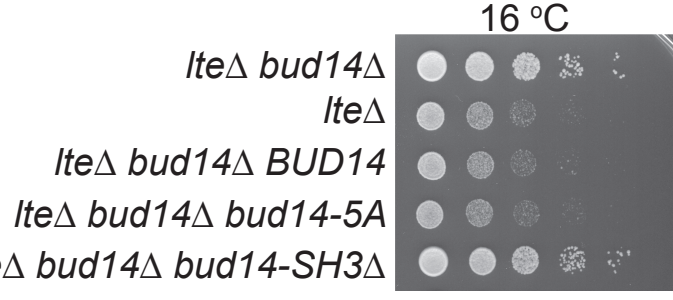

$23^{\circ} \mathrm{C}$ $30^{\circ} \mathrm{C}$

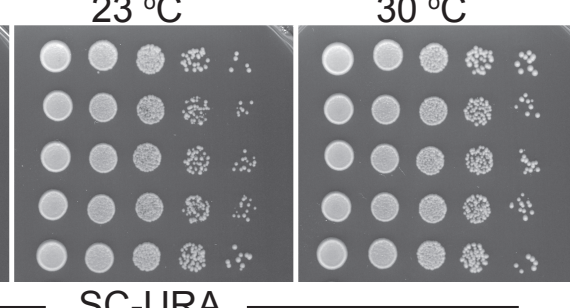

$16{ }^{\circ} \mathrm{C}$

G

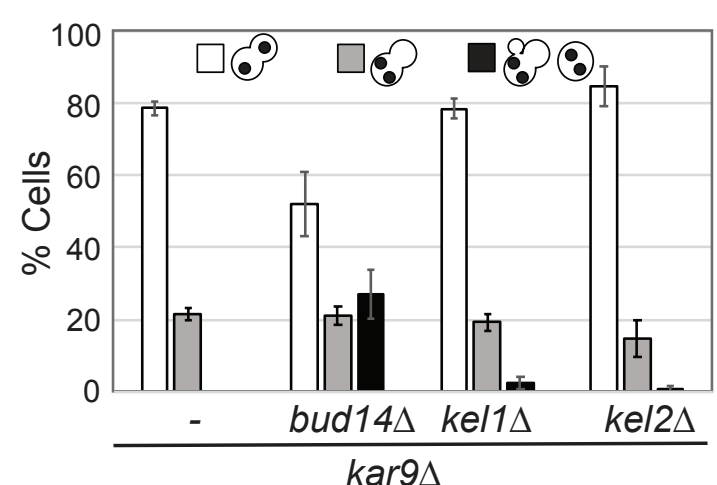

$\mathrm{H}$

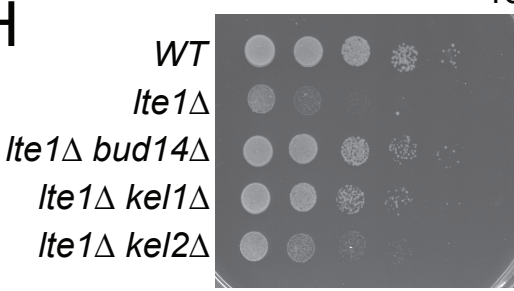

5-FOA'

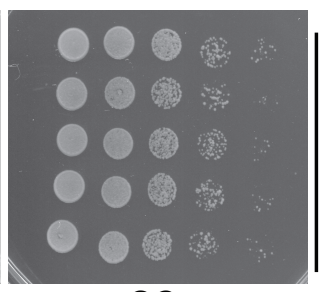

pRS316-

LTE1

$30^{\circ} \mathrm{C}$

Ite1 $1 \Delta$ spo12 $\Delta$ Ite $1 \Delta$ spo12 $\Delta$ kel1 $\Delta$ Ite $1 \Delta$ spo $12 \Delta$ kel2 $\Delta$ Ite $1 \Delta$ spo12 $\Delta$ bud $14 \Delta$

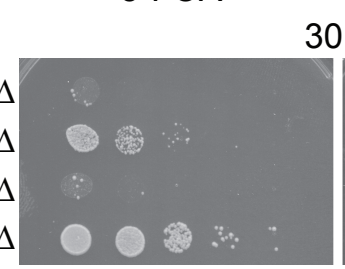

5-FOA'
SC

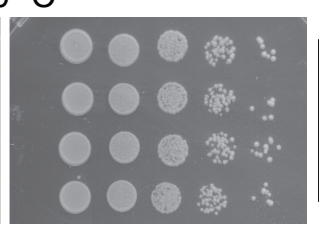

pRS316LTE1 
bioRxiv preprint doi: https://doi org/10.1101/2020.08 30 273946; this version posted November 19,2020. The copyright holder for this Figurepreprint (which was not certified by peer review) is the author/funder, who has granted bioRxiv a license to display the preprint in

A

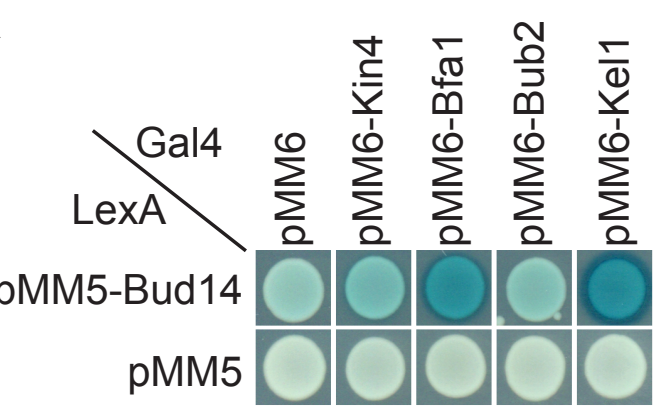

B

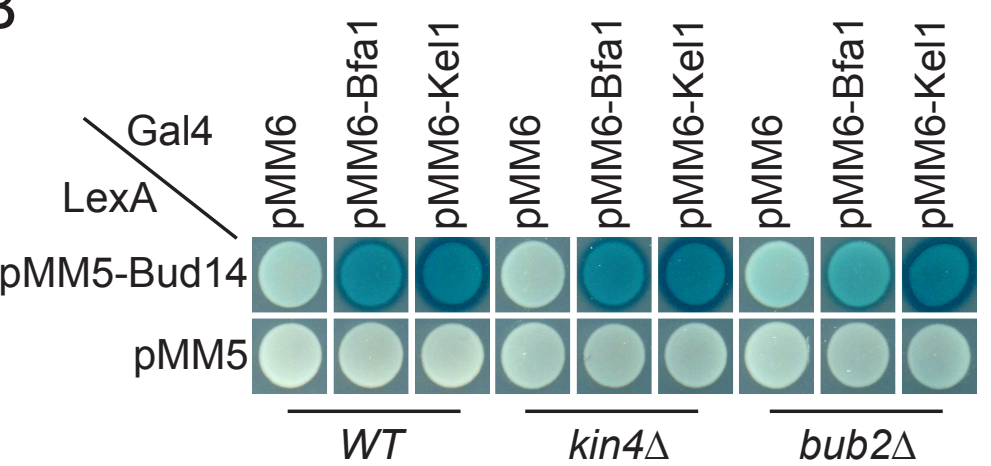


bioRxiv preprint doi: https://doi.org/10.1101/2020.08.30.273946; this version posted November 19,2020 . The copyright holder for this Figure Eeprint (which was not certified by peer review) is the author/funder, who has granted bioRxiv a license to display the preprint in

A

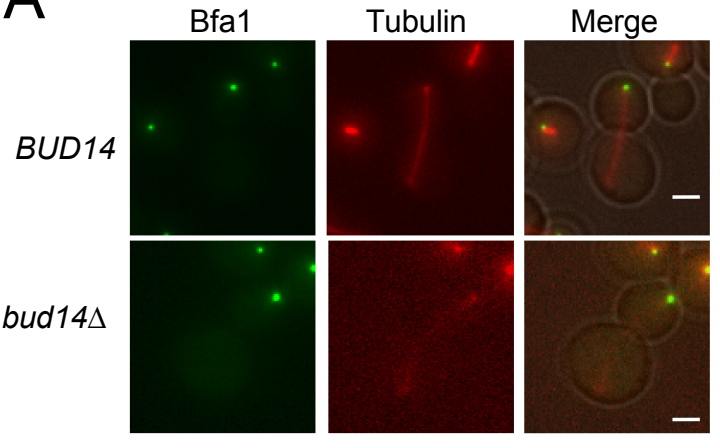

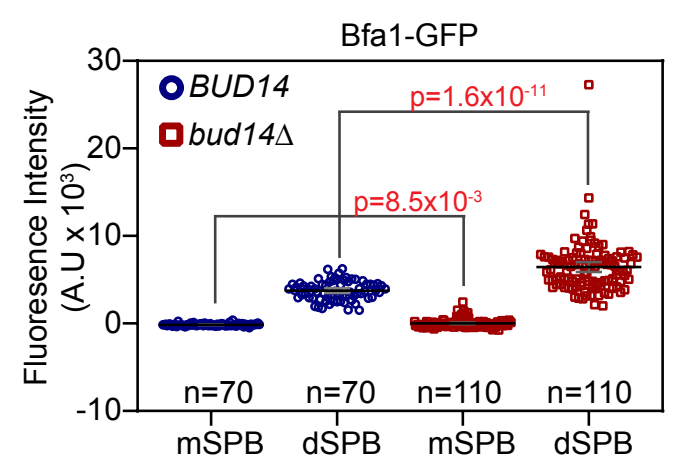

B

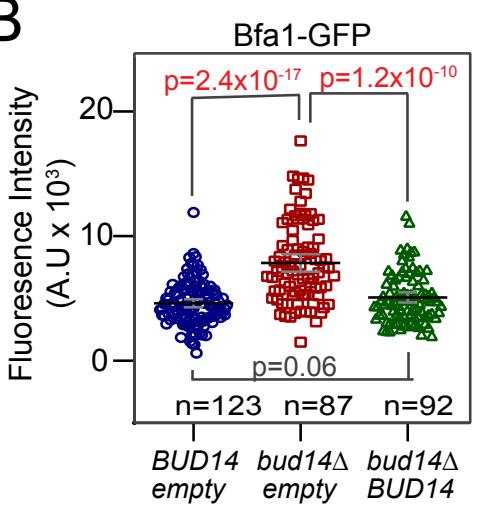

C

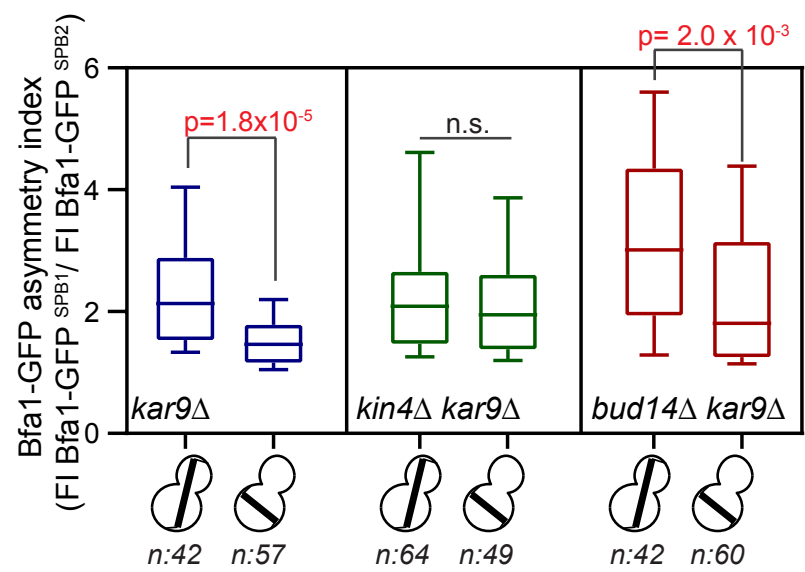

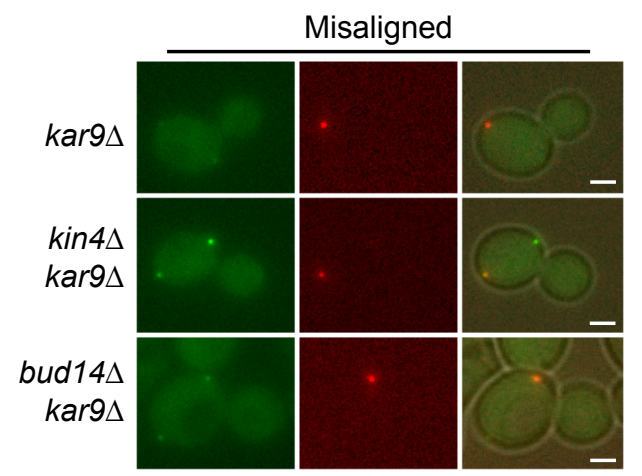

Bfa1-

GFP
Spc42eqFP

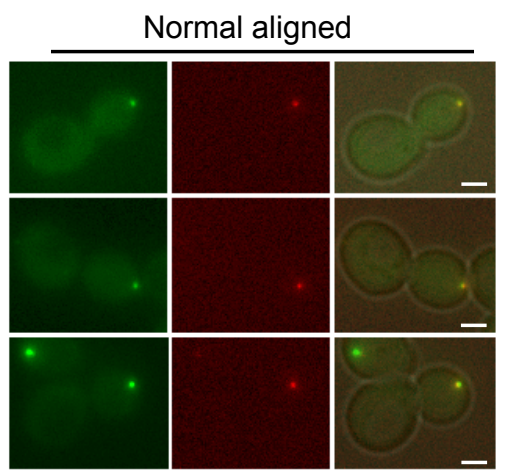

Bfa1GFP
Spc42eqFP 
bioRxiv preprint doi: https://doi.org/10.1101/2020.08.30.273946; this version posted November 19,2020 . The copyright holder for this Figure Figure 6 perpetuity. It is made available under aCC-BY-NC-ND 4.0 International license.

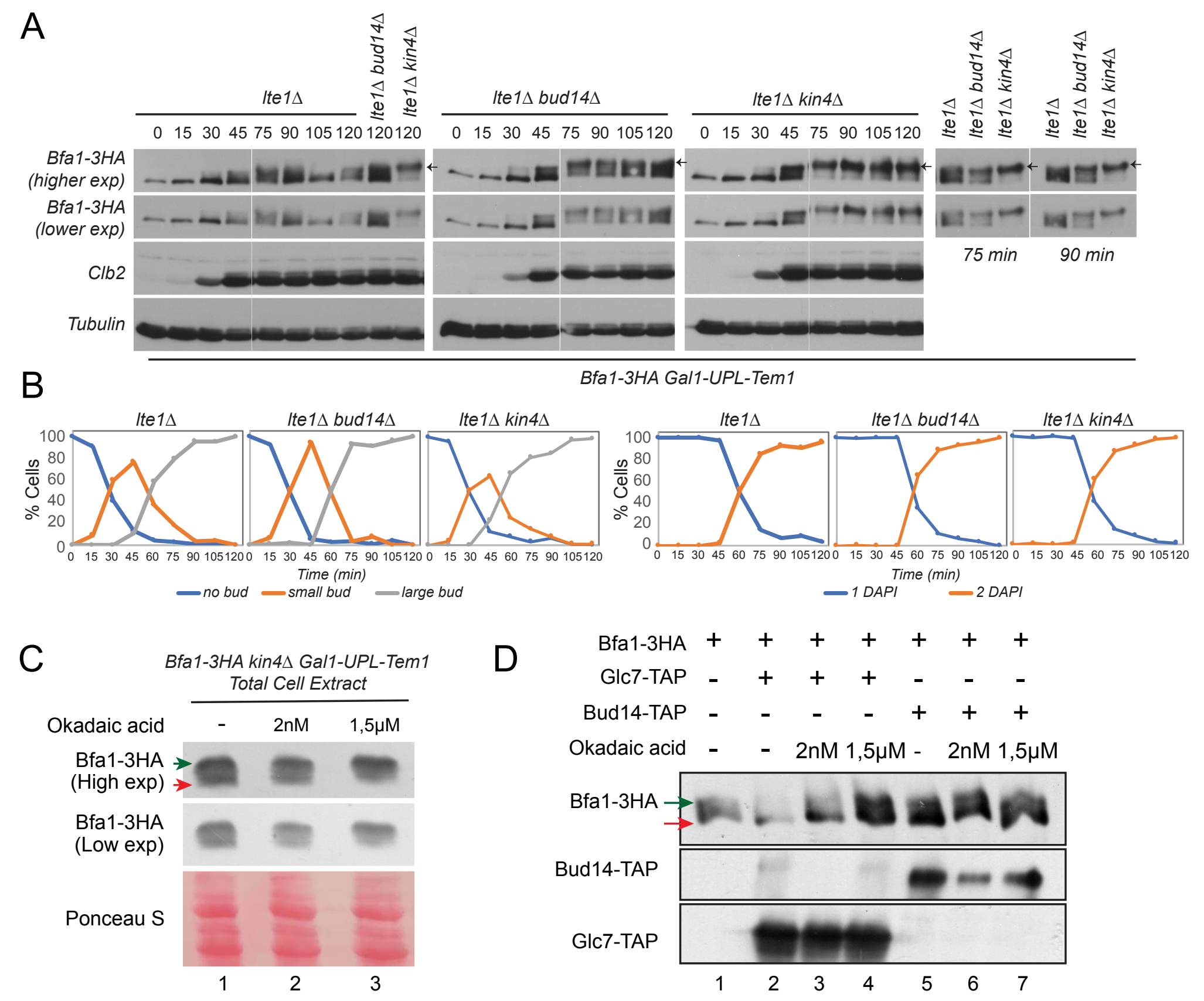


bioRxiv preprint doi: https://doi.org/10.1101/2020.08.30.273946; this version posted November 19,2020 . The copyright holder for this

Figure $7^{p}$

preprint (which was not certified by peer review) is the author/funder, who has granted bioRxiv a license to display the preprint in

A

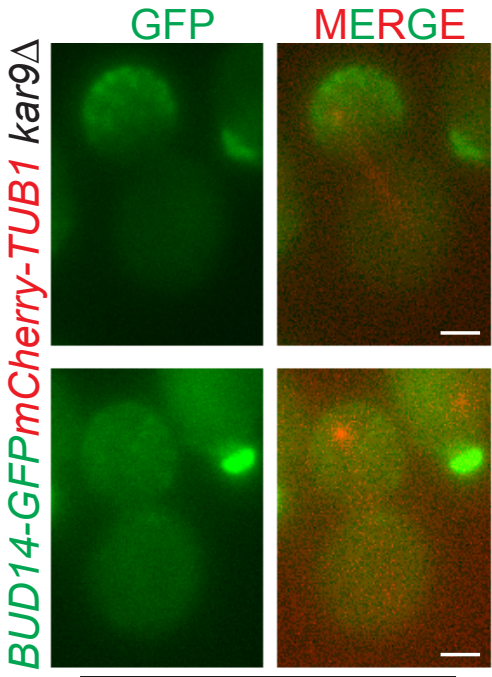

Normal aligned
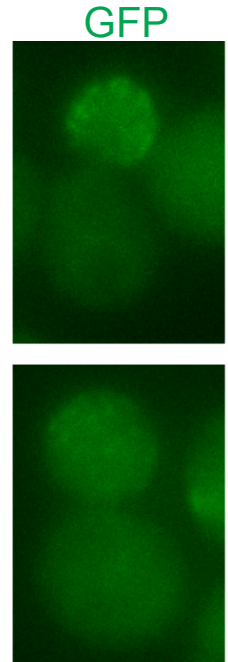

Misaligned
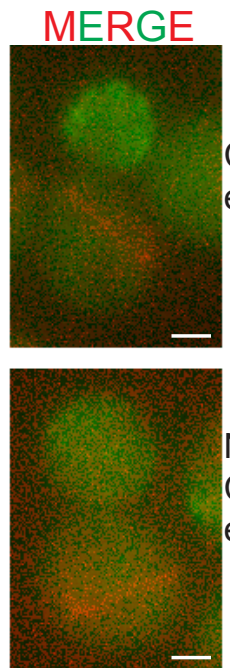

Not Cortex enriched

Cortex enriched

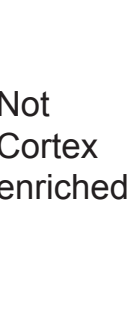

B BUD14-GFP mCherry-TUB1 kar9A
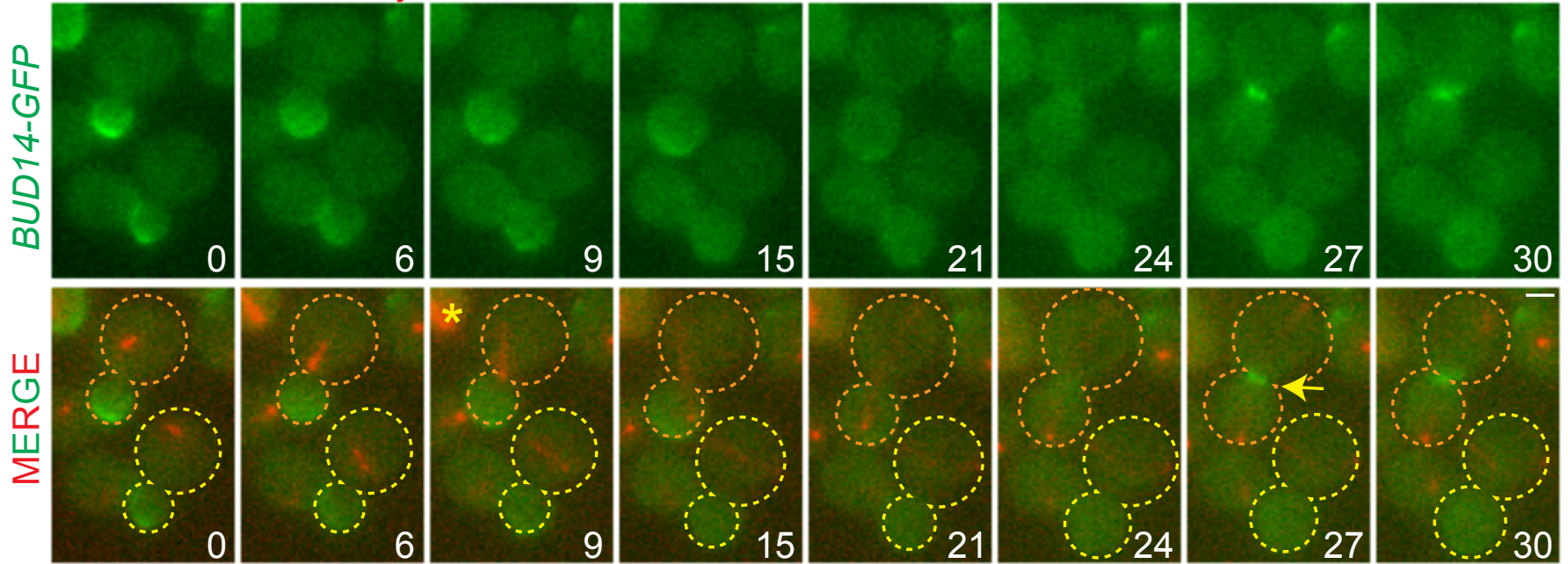
bioRxiv preprint doi: https://doi.org/10.1101/2020.08 30 273946; this version posted November 19,2020. The copyright holder for this preprint (which was not certified by peer review) is the author/funder, who has granted bioRxiv a license to display the preprint in Figure 8 perpetuity. It is made available under aCC-BY-NC-ND 4.0 International license.

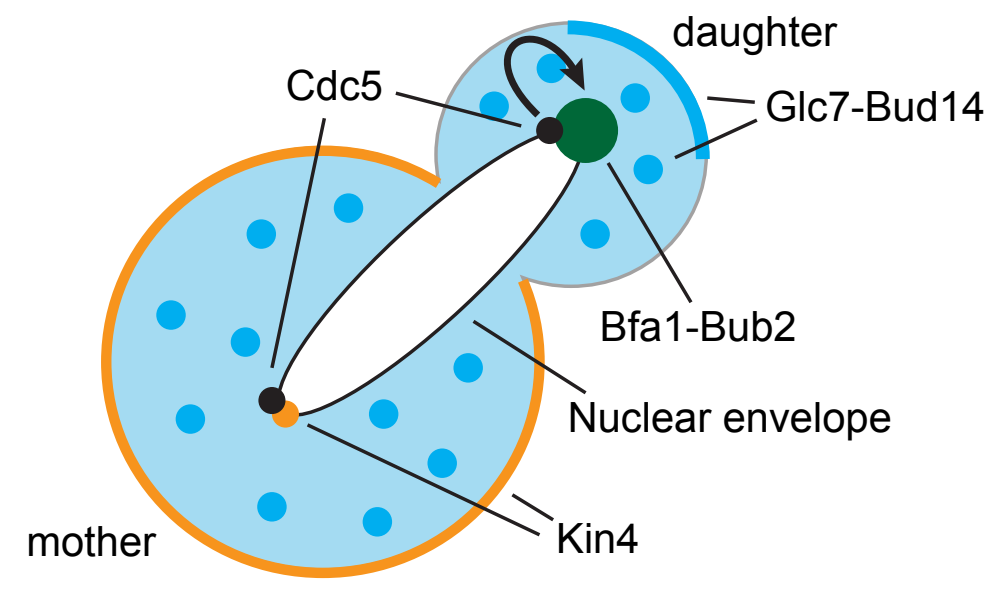

Normal aligned spindle

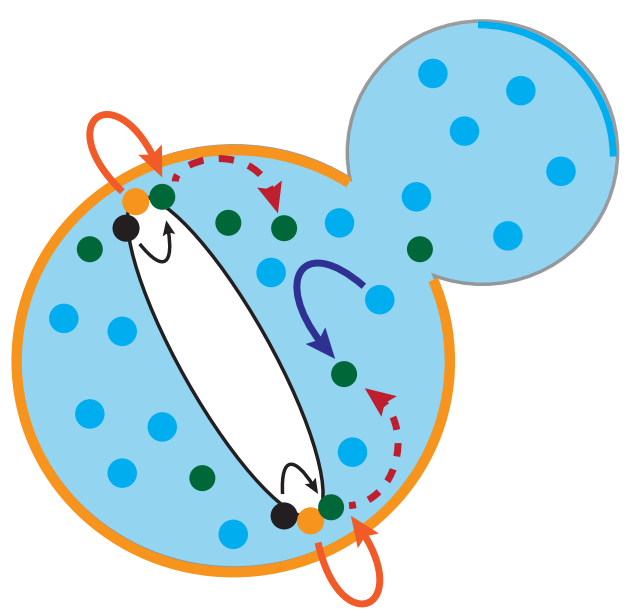

Misaligned spindle 